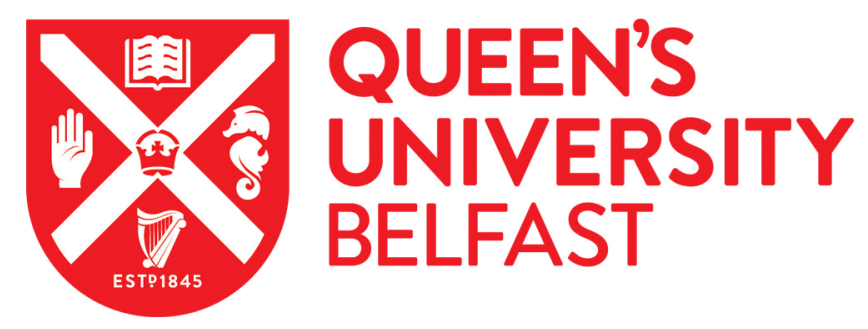

\title{
Modeling Heterogeneity in Patients' Preferences for Psoriasis Treatments in a Multicountry Study: A Comparison Between Random- Parameters Logit and Latent Class Approaches
}

Boeri, M., Saure, D., Schacht, A., Riedl, E., \& Hauber, B. (2020). Modeling Heterogeneity in Patients'

Preferences for Psoriasis Treatments in a Multicountry Study: A Comparison Between Random-Parameters Logit and Latent Class Approaches. PharmacoEconomics, 38(6), 593-606. https://doi.org/10.1007/s40273-02000894-7

Published in:

PharmacoEconomics

Document Version:

Peer reviewed version

Queen's University Belfast - Research Portal:

Link to publication record in Queen's University Belfast Research Portal

Publisher rights

Copyright 2021 Springer Nature Switzerland AG.

This work is made available online in accordance with the publisher's policies. Please refer to any applicable terms of use of the publisher.

\section{General rights}

Copyright for the publications made accessible via the Queen's University Belfast Research Portal is retained by the author(s) and / or other copyright owners and it is a condition of accessing these publications that users recognise and abide by the legal requirements associated with these rights.

\section{Take down policy}

The Research Portal is Queen's institutional repository that provides access to Queen's research output. Every effort has been made to ensure that content in the Research Portal does not infringe any person's rights, or applicable UK laws. If you discover content in the

Research Portal that you believe breaches copyright or violates any law, please contact openaccess@qub.ac.uk. 


\section{Modeling Heterogeneity in Patients' Preferences for Psoriasis Treatments in a Multicountry Study: A Comparison Between Random-Parameters Logit and \\ Latent Class Approaches}

Marco Boeri, $\mathrm{PhD}^{1}$, Daniel Saure, $\mathrm{PhD}^{2}$, Alexander Schacht, $\mathrm{PhD}^{2}$, Elisabeth Riedl MD $\mathrm{MD}^{3}$ Brett Hauber, $\mathrm{PhD}^{4}$

${ }^{1}$ RTI Health Solutions, Health Preference Assessment, Belfast, UK;

${ }^{2}$ Eli Lilly and Company, Bad Homburg, Germany;

${ }^{3}$ Eli Lilly and Company, Vienna, Austria;

${ }^{4}$ RTI Health Solutions, Health Preference Assessment, Research Triangle Park, NC, USA;

Corresponding Author:

Marco Boeri

RTI Health Solutions, Forsyth House, Cromac Square Belfast (UK) BT2 8LA

E-mail: mboeri@rti.org, Telephone: +44 (0)161 4476016

Target Journal: Pharmacoeconomics

Running Head: Modeling patient preference for psoriasis therapy

Word Count: 4,900

Number of Tables and Figures: 4 tables, 4 figures

Financial support for this study was provided by Eli Lilly and Company. The funding agreement ensured the authors' independence in designing the study, interpreting the data, writing, and publishing the report. The following authors are employed by the sponsor: Daniel Saure and Elisabeth Riedl. Alexander Schacht was employee of Lilly at the time of writing the manuscript and is now employee of UCB Biosciences. Marco Boeri and Brett Hauber are employees of RTI Health Solutions. The initial work from which the manuscript was generated was presented last year at the PSI conference in Amsterdam (Saure D, Boeri M, Thorn K, Schacht A. Make conjoint analyses your standard approach understand how patient preferences vary across different subgroups. Presented at the 2018 Promoting Statistical Insight (PSI) Conference; June 5, 2018. Amsterdam, The Netherlands). The presentation included initial results then used as starting point for this manuscript. 


\section{$1 \quad$ Abstract}

Background: Either a random-parameters logit (RPL) or a latent class (LC) model can be used to model or explain preference heterogeneity in discrete-choice experiment (DCE) data. The former assumes continuous distribution of preferences across the sample, while the latter assumes a discrete distribution. This study compared RPL and LC models to explore preference heterogeneity when analyzing patient preferences for psoriasis treatments.

Methods: Using DCE data collected from respondents with moderate-to-severe plaque psoriasis, we calculated and compared preference weights derived from RPL and LC models. We then compared how RPL and LC explain preference heterogeneity by exploring differences across subgroups defined by observed characteristics (i.e., country, age, gender, marital status, and psoriasis severity).

Results: While RPL and LC models resulted in the same mean preference weights, different preferenceheterogeneity patterns emerged from the two approaches. In both models, country of residence and self-reported disease severity could be linked to systematic differences in preferences. The RPL also identified gender and marital status, but not age, as sources of heterogeneity; the LC membership probability model indicated that age was a significant factor, but not gender or marital status.

Conclusions: Using data from a psoriasis patient survey to compare two widely used methods for exploring heterogeneity identified differences in results between stated-preferences-subgroup analysis in the RPL model and inclusion of subgroup characteristics in the class membership probability function of the LC model. Researchers should model data using the most adaptable approach to address the initial study question.

\section{Keywords}

Plaque psoriasis; discrete-choice experiments; random parameters logit; latent class analysis; preference heterogeneity 


\section{Key points}

- There is a growing interest in alternative ways to control for and model differences in preferences.

- This study compared for the first time in health care preference assessment the results obtained by modelling data from a discrete choice experiment with a random parameters logit (RPL) model with independent random parameters and with a latent class (LC) model.

- Initial comparison of the average results from both RPL and LC models revealed similar mean preference weights and attribute importance across models; however, we also found that the RPL subgroup analysis and the patterns highlighted in the LC model could lead to different implications.

- On the basis of the results, we suggest that the final model should be determined by the type of research questions:

- If the objective of the research is to identify segments in a population for whom alternative approaches to treatment or communication are to be developed, then LC analysis is very likely the correct approach.

- If instead the objective of the study is to quantify the preferences for a population, an RPL model may be most appropriate. 


\section{Introduction}

Discrete-choice experiments (DCEs) have been widely employed in recent decades to quantify patients' and physicians' treatment preferences and the tradeoffs they are willing to accept between the benefits and risks of those treatments in a range of therapeutic areas [1-5]. For diseases such as psoriasis, a chronic inflammatory skin disease with a wide armamentarium of treatment options available, DCEs can be used to identify the tradeoffs patients are willing to make among benefits, risks, and other attributes (e.g., administration form) when deciding between therapeutic alternatives. A number of studies explored preferences for psoriasis treatments and their characterization by various attributes (e.g., efficacy, safety, and mode of administration). While some studies focused on preferences for systemic treatments only [6-10], others considered preferences for systemic and nonsystemic treatments (e.g., [11-14]). Most studies were restricted to one or two countries and contained a sample size below 500 respondents [6, 7, 11-13, 15-20], with the exception of the study by Fairchild et al. [9], who reported a sample of 925 respondents.

In the early applications of DCEs, data were analyzed using a conditional multinomial logit model developed by McFadden [21]. Most DCE studies in health care 3-5] are based on the publication by Train [22] emphasizing the importance of controlling for preference heterogeneity to avoid bias in coefficient estimates. Data in many early applications of DCEs in health were analyzed by assuming continuous heterogeneity in preferences and estimating a random-parameters logit (RPL) model with independent random parameters. The RPL model assumes that there is a continuous distribution of each preference parameter estimated in the model that reflects the distribution of preferences across respondents. These distributions can be assumed to be uncorrelated (i.e., independent from each other) or correlated. However, most existing applications of the RPL model do not include correlations across randomly distributed parameters in RPL applications because DCE data often are not sufficient for model identification. In contrast to the RPL model, a latent class (LC) model assumes that there is a finite number of discrete preference segments and that each respondent has a probability of being in each segment. In 1996, the first DCE in health using an LC model for data analysis was published [23], followed by over a decade with only two subsequent publications using LC modeling. Starting in 2011 [24], LC modeling started to be used more widely, with a continuous increase in the number of published studies applying this methodology since then 25].

Still, empirical evidence on the similarities and differences resulting from RPL and LC models to account for preference heterogeneity is lacking. Zhou et al. [25] identified 78 DCE studies that used LC analysis. Among these 78 studies, 26 (33.3\%) reported only the estimated results from the LC model, 40 studies (51.3\%) reported aggregate preferences from a logit model (conditional or multinomial) in addition to the LC results, and 9 studies (11.5\%) reported individual preference weights estimated using a hierarchical Bayesian approach in addition to the LC results. Both LC and RPL models were used in 12 studies (15.4\%), and 55.8\% of those studies reported information about the statistical methods used to compare model results. However, none of these studies systematically compared the impact of respondent characteristics on preference heterogeneity between the two different modeling approaches or assessed whether the same conclusions about systematic preference heterogeneity were similar between the two models. Assumptions about the distribution of preference heterogeneity may have analytic 
implications; thus, Zhou et al. 25] have recommended that more studies compare alternative model specifications and that guidelines on such comparisons should be developed.

This study compared several RPL models, each with independent random parameters, in which subgroups were analyzed by estimating a separate set of parameters for each subgroup when the subgroups were defined by observed respondent characteristics, and an LC model using the same observed characteristics as explanatory variables in the class probability function that probabilistically assigns respondents to each LC identified in the data. Discrete-choice experiment data from a multinational psoriasis survey were used in this model.

\section{Methods}

\subsection{Study Design and Data Collection}

The data were collected in a cross-sectional survey study, using a DCE survey instrument. In the DCE survey instrument, hypothetical treatments for plaque psoriasis were defined by the following attributes with varying levels: mode and frequency of application ("dosage form"), time to reach clinically meaningful results ("time to reach results"), reduction in psoriasis lesions, including plaques ("results: skin"), reduction in itching ("results: itching"), risk of moderate-to-severe side effects ("risk of impairing side effects"), and the frequency and duration with which side effects appear ("side effects manifestation" in Table 1, presented to respondents as "appearance of side effects") (Table 1).

As summarized in Figure 1, the online survey instrument was conducted in 18 countries and included 1,966 respondents with self-reported psoriasis. Enrollment criteria were defined as age 18 to 75 years, diagnosis of psoriasis by a dermatologist, current or past affected body surface area (BSA) $\geq 3 \%$, disease duration $\geq 12$ months, current topical therapy, phototherapy (including psoralen and ultraviolet A), and conventional systemic or biologic therapy for psoriasis (concomitant systemic therapy for rheumatoid arthritis, Crohn's disease, or ulcerative colitis were exclusion criteria). As part of the same survey instrument, a DCE was administered to 1,155 respondents in five of the 18 countries: Canada, France, Spain, the United Kingdom, and Italy. In total, 32 respondents were excluded because they either did not answer any choice questions in the DCE, answered only the DCE questions but not any others in the survey, or did not vary their answers to the DCE questions, yielding a final analysis sample of 1,123 respondents.

Each respondent was presented with a series of 12 choice questions that were randomly selected from a larger design including 100 blocks generated using Sawtooth Software [26]. The different hypothetical treatment profiles in the DCE were defined by levels of the attributes mentioned previously (see Table 1). In each choice question, respondents were asked to select from among three unlabeled hypothetical treatments. An example of a choice question is presented in Figure 2. 


\subsection{Analysis}

Preference data from DCEs are based on the assumptions of the random utility framework [27-28] which asserts that, when facing a choice, respondents select the option that maximizes their utility, defined by the following underlying utility function:

$$
U_{n i t}=V_{n i t}+\varepsilon_{n i t}=\sum_{k=1}^{K}\left[\left(\beta_{k}\right) X_{k n i t}\right]+\varepsilon_{n i t}
$$

This equation describes the utility function for respondent $n$, alternative $i$, and choice occasion $t=1,2, \ldots, 12$ (as each respondent answered 12 choice questions). The utility function comprises an observable part,

$V_{n i t}=\sum_{k=1}^{K}\left[\left(\beta_{k}\right) X_{k n i t}\right]$, and a random error term, $\varepsilon_{n i t} . X_{k n i t}$ is the level of attribute $k=1 . K$ attributes, as reported in Table 1 , and $\beta_{k}$ is the corresponding set of parameters to be estimated in the model.

The observable part of the utility function $(V)$ includes all attribute levels specified as effects-coded variables, so that the mean effect for each attribute was normalized at zero. To have an identifiable model, one level for each attribute was excluded from estimation and recovered as the negative sum of the coefficients on the nonexcluded levels of the attribute. The delta method was then used to compute the standard error of the coefficients on the omitted levels by an approximation based on a Taylor series. The following main-effects utility model was used in estimation:

$$
\begin{aligned}
V_{n i t} & =\beta_{\mathrm{DOSE} 1} \times \mathrm{DOSE} 1+\beta_{\mathrm{DOSE} 2} \times \mathrm{DOSE} 2+\beta_{\mathrm{DOSE} 3} \times \mathrm{DOSE} 3+\beta_{\mathrm{DOSE} 4} \times \mathrm{DOSE} 4 \\
& +\beta_{\mathrm{TIME} 1} \times \mathrm{TIME} 1+\beta_{\mathrm{TIME} 2} \times \mathrm{TIME} 2+\beta_{\mathrm{TIME} 3} \times \mathrm{TIME} 3 \\
& +\beta_{\mathrm{SKIN} 1} \times \mathrm{SKIN} 1+\beta_{\mathrm{SKIN} 2} \times \mathrm{SKIN} 2+\beta_{\mathrm{SKIN} 3} \times \mathrm{SKIN} 3 \\
& +\beta_{\mathrm{ITCH} 1} \times \mathrm{ITCH} 1+\beta_{\mathrm{ITCH} 2} \times \mathrm{ITCH} 2 \\
& +\beta_{\mathrm{IMP} 1} \times \mathrm{IMP} 1+\beta_{\mathrm{IMP} 2} \times \mathrm{IMP} 2+\beta_{\mathrm{IMP} 3} \times \mathrm{IMP} 3 \\
& +\beta_{\mathrm{APP} 1} \times \mathrm{APP} 1+\beta_{\mathrm{APP} 2} \times \mathrm{APP} 2
\end{aligned}
$$

Assuming that $\varepsilon_{n i t}$ follows a type 1 extreme value distribution, the probability of choosing a given alternative in each choice question can be described by a conditional multinomial logit function:

$\operatorname{Pr}\left(Y_{j n t}^{i}\right)=\frac{\exp \left(\sum_{k=1}^{K}\left[\beta_{k} X_{k n i t}\right]\right)}{\sum_{j=1}^{J} \exp \left(\sum_{k=1}^{K}\left[\beta_{k} X_{k n j t}\right]\right)}$

where $Y_{j n t}^{i}$ is the choice of alternative $i$ among $j$ alternatives by respondent $n$ for the choice question $t$ in the sequence of choice questions with which the respondent $n$ was presented. Unexplained variation in preferences 
across the sample can bias estimates in conventional conditional multinomial logit models. Mixed multinomial logit models 29] are extensions of the conditional multinomial logit model and are commonly used in preference analysis to control for unexplained heterogeneity, as they avoid potential estimation bias by estimating a distribution of preferences around each parameter that accounts for variations among individual preferences. There are two mixed logit model specifications commonly used to control for unexplained heterogeneity in preference analysis: one that assumes continuous distribution of preference across respondents (e.g., RPL model) and one that assumes discrete distribution of preferences across respondents (e.g., LC model) [30].

\subsubsection{Random-Parameters Logit Model}

Random-parameters logit (RPL) models generalize the conditional multinomial logit model by allowing the coefficients used to describe the preference weights for each attribute level to vary randomly across respondents following a continuous distribution. The model still assumes that, for each individual, the choice probability is a logit, but the sample probability requires integrating over a distribution of preferences specified by the analyst. Generally, most studies in health assume a normal distribution for all attribute levels, but this is not a constraint of the model; other distributions can be used. Once a functional form has been determined for the distribution of individual preferences, it is possible to specify the variance-covariance matrix of the RPL model in a manner consistent with either independence of preference intensities (by identifying only its diagonal values) or correlation (by allowing for nonzero off-diagonal values). The latter can be used to accommodate for both preference and variance (often referred to as scale) heterogeneity [31]. However, accounting for correlations among random parameters is more complex and requires more data to be identified. Most existing applications of the RPL model do not include correlations across randomly distributed parameters in RPL applications because DCE data often are not sufficient for model identification. In this study, we assumed that that random parameters were independent. The estimated probability for choice $Y_{j n t}^{i}$ of alternative $i$ among $j$ alternatives by respondent $n$ represented below takes into account the panel nature of the data by incorporating the sequence of observed choices $(T=1 \ldots 12)$ :

$$
\operatorname{Prob}\left[Y_{j n 1}^{i}, \ldots, Y_{j n T}^{i}\right]=\int \prod_{t=1}^{T} \frac{\exp \left(\sum_{k=1}^{K}\left[\left(\beta_{k}+\eta_{k}\right) X_{k n i t}\right]\right)}{\sum_{j=1}^{J} \exp \left(\sum_{k=1}^{K}\left[\left(\beta_{k}+\eta_{k}\right) X_{k j t}\right]\right)} f\left(\eta_{1 . k}\right) d \eta_{1 . k}
$$

where $\eta_{k}$ is the random component that captures heterogeneity in the RPL model (under the assumption of normally distributed random components, this represents the standard deviation of the distribution).

The integral in the equation above is approximated numerically using simulation methods [32] based on quasirandom Halton draws or modified hypercube sampling draws [33]. The maximized function is therefore called a simulated maximum log-likelihood function.

\subsubsection{Latent Class Model}

Latent class models generalize the conditional multinomial logit model and control for unexplained preference heterogeneity by assuming the presence of latent segments in the sample with systematically different preferences 
[34]. Therefore, the main difference between LC and RPL is that LC models assume a discrete, rather than a continuous, mixing distribution to describe heterogeneity in respondents' choices and preferences. Latent class models assume that respondents can be probabilistically assigned to a finite set of $\mathrm{C}$ classes based on the pattern of their choices. Each class is characterized by a unique class-specific vector of utility parameters $\beta_{c}$ for the attribute levels in the choice task. Thus, within classes, respondents are assumed to have identical preferences; however, across classes the preference structure is allowed to vary systematically. Defining the membership probabilities $\pi$ for each class $c$ according to a multinomial logit process, we have:

$$
\operatorname{Prob}\left[Y_{j n 1}^{i}, \ldots, Y_{j n T}^{i}\right]=\sum_{c=1}^{C} \pi_{c} \prod_{t=1}^{T} \frac{\exp \left(\sum_{k=1}^{K}\left[\left(\beta_{c k}\right) X_{k n i t}\right]\right)}{\sum_{j=1}^{J} \exp \left(\sum_{k=1}^{K}\left[\left(\beta_{c k}\right) X_{k n j t}\right]\right)}
$$

In estimation, only C-1 sets of coefficients can be independently identified, while one arbitrary class $\mathrm{c}$ is constrained to zero. With this specification, the LC models do not assign each respondent to a class. Instead, they assign a class membership probability to each respondent. The model output includes the average class membership probability across the sample for each class.

The first and one of the most important steps when considering an LC analysis is to define the optimal number of classes for the data. We examined the Bayesian information criterion (BIC) [35] the Akaike information criterion (AIC) [36], the 3AIC and the corrected AIC, variations of the AIC that penalize differently for the number of parameters used [37]. These criteria fail some of the regularity conditions for a valid test under the null hypothesis [38-39], and therefore, researchers may need additional strategies to determine the optimal number of classes for their studies.

\subsubsection{Modeling Preference Heterogeneity}

Preference heterogeneity is controlled for in both RPL and LC models, but the source of heterogeneity is not explored. Subgroup analyses can reveal how different observed respondent characteristics are correlated systematically with differences in preferences across the sample.

In this study, preference heterogeneity was explored among prespecified sets of subgroups in the RPL model. Differences in preferences across six sets of subgroups (country of residence [Canada, France, Italy, Spain, UK], age [ $<30$ years, $\geq 30$ years], median age [ $<39$ years, $\geq 39$ years], gender [mail, female], marital status [married, single, other], and psoriasis severity [BSA <3\%, BSA 3\%-10\%, BSA >10\%]) were tested in this study. For subgroups in which patients could be categorized into one of two mutually exclusive subgroups (age, gender), analyses were conducted by interacting each attribute level in the model with a dummy-coded variable to identify respondents who were part of one subgroup in a pair (see Table 2) and adding all interaction terms to the original RPL model. For the subgroup sets with 3 subgroups (marital status, psoriasis severity), two sets of dummy-coded interaction terms were included. For country of residence, four sets of dummy-coded interaction terms were included. The estimated parameters on the interaction terms can be interpreted as the difference in preferences between the subgroup of interest (dummy 
variable $=1$ ) and the reference group (dummy variable $=0$ ). Finally, systematic differences were tested between two subgroups at a time with a Wald test (e.g., by testing the hypothesis that all coefficients on the dummy-variable interactions were zero).

LC models can also be used to explore preference heterogeneity based on specific subgroups of interest by including covariates in the membership probability function:

$\pi_{c}=\frac{\exp \left(\alpha_{c}+\gamma_{c} z_{n}\right)}{\sum_{c=1}^{C} \exp \left(\alpha_{c}+\gamma_{c} z_{n}\right)}$

where $z_{n}$ is a vector of covariates characterizing respondent $n$ (see Table 2), and $\gamma_{c}$ is the vector of associated parameters, while $\alpha_{c}$ is a class-specific constant.

The analyses were conducted using NLOGIT 5.0 (Econometric software, Plainview, NY).

\section{$5 \quad$ Results}

\subsection{Respondent Characteristics}

Data from 1,123 respondents who completed the DCE survey instrument were included in the final analysis. Detailed demographic information of study participants is shown in Table 3. In brief, 55.1\% of participants were female, and the mean age was 40.6 years. Most respondents reported full-time employment (61.9\%), and 50.3\% were married.

\subsection{Preference Analysis: Mean Preference Weights}

Parameter estimates from the RPL and LC models yield preference weights from which mean conditional relative attribute importance estimates can be derived. The preference weights across classes in the LC model (i.e., the average of the class parameter estimates weighted by the class membership probability) can be compared directly with the RPL output.

The parameter estimates from the RPL model, including the calculated parameter estimate for the omitted level of each attribute, are presented in Supplemental Table A-1. These estimates include the preference weights (mean preference estimates for the sample), their standard deviations, and $P$ values for both means and standard deviations. A statistically significant estimate of the standard deviation of the mean preference weight for an attribute level indicates that the preference weight for that attribute level varied across respondents in the sample. The parameter estimates from the LC model, including the calculated parameter estimate for the omitted level of each attribute, are presented in Supplemental Table A-2. Following the various goodness-of-fit measures presented for the various LC model specifications, as well as for the multinomial logit model and the RPL in Supplemental Table A-3, the LC 
model with four classes was considered the optimal model specification for this data set because it generated the best BIC and convergence for the other AIC measures (Supplemental Figure A-1).

Figure 3 plots the mean preference weight estimate for each attribute level derived from both the RPL and the LC models. In this analysis, the RPL and the LC models resulted in identical (or highly similar) mean preference weights for the full sample. Both models indicate that, with respect to dosage form, respondents on average preferred tablets (once a week) to frequent (1-2 times per month) or infrequent (4 times a year) injections, ointment (daily), and phototherapy (in phases, several times a week). In addition, mean preference estimates for all naturally ordered attribute levels were ordered as one would assume. For example, shorter times to achieve clinically meaningful results were preferred to longer times, greater reductions in psoriasis lesions were preferred to smaller reductions, and lower risks of moderate-to-severe side effects were preferred to higher risks.

The change in utility associated with a change in the levels of each attribute is represented by the vertical distance between the preference weights for any two levels of that attribute. Larger differences between preference weights indicate that respondents viewed the change as having a relatively greater effect on overall utility. For example, the results show that an increase in lesion reduction from 50\% to $100 \%$ yields an increase in utility of approximately 1.5. Likewise, a reduction in the time to reach clinically meaningful results from 6 months to 2 weeks yields an increase in utility of approximately 0.4 . Therefore, an increase in lesion reduction from $50 \%$ to $100 \%$ is preferred to a reduction in the time to reach clinically meaningful results from 6 months to 2 weeks because it results in an increase in utility that is approximately four times greater than a reduction in the time to reach clinically meaningful results from 6 months to 2 weeks.

Finally, the vertical distance between the most-preferred and least-preferred levels of an attribute is a measure of conditional relative importance of that attribute - the importance of an attribute relative to the other attributes in the study given the range of levels of that attribute. Among the full sample, lesion reduction was, on average, approximately as important as the risk of moderate-to-severe side effects, while the remaining attributes were relatively less important.

In contrast with the output of the RPL model, which includes standard deviations of the normal distributions assumed for each parameter related to the attribute levels, the output of the LC model directly creates groups (or classes) of preferences to which respondents are assigned probabilistically. As presented in Supplemental Table A-2, four classes were identified in the data by the LC model, showing, similar to the RPL model, that preference heterogeneity is present in the sample. Class-specific preference weights retrieved from the LC model are presented in Figure 4. The preference weights for the respondents likely to be in class 1 (approximately $35.0 \%$ of the sample) are shown in blue and indicate a strong preference for lower risk of moderate-to-severe side effects. Preference weights for likely class 2 respondents (approximately $36 \%$ of the sample) are indicated in red and indicate that these respondents were somewhat indifferent among the attributes. Preference weights for likely class 3 respondents (approximately $20 \%$ of the sample) are shown in green and indicate that these respondents strongly preferred higher 
efficacy. Finally, preference weights for likely class 4 respondents (approximately $14 \%$ of the sample) are presented in orange and indicate that these respondents were strongly averse to injections.

\subsection{Modeling Preference Heterogeneity}

This section presents model specifications of both RPL and LC models that attempt to explain preference heterogeneity based on observed respondent characteristics.

\subsubsection{Subgroup Analysis in the Random-Parameters Logit Model}

Table 2 summarizes the subgroups considered and the sample size of each subgroup included in the analysis, and Table 4 presents the $P$ values associated with the chi-squared distribution used to test for systematic differences in the RPL subgroups analysis and the membership probability model output of the LC model.

Focusing our attention firstly on the RPL model, results of the test for whether the interaction terms created by interacting each subgroup-specific dummy variable were jointly statistically significant indicate whether preferences between subgroups within a subgroup pair were statically significantly systematically different. The joint test may indicate that the set of interaction terms is not jointly statistically significant, but individual interaction terms could be statistically significant. Therefore, this test is used to identify systematic differences in preferences between subgroup pairs. These results indicate that preferences were systematically different between male and female respondents $(P<0.001)$ (Supplemental Figure B-1), but not statistically significantly systematically different between respondents younger than the median age of 39 years and respondents who were the median age of 39 years or older $(P=0.439)$ (Supplemental Figure B-2). We also tested differences between respondents younger than 30 years of age and respondents 30 years of age or older but did not find a statistical difference $(P=0.104)$ (Supplemental Figure B-3).

The same test was performed on the subgroups generated by dividing the sample into categories of marital status (married, single, and other) and three severity subgroups based on percentage of BSA affected (2\% or lower, between $3 \%$ and $10 \%$, and greater than 10\%). Single and married respondents did not have statistically significantly systematically different preferences $(P=0.116)$; however, while married respondents and respondents with other marital status (neither single nor married) were not systematically different $(P=0.157)$, single respondents had systematically different preferences from respondents with other marital status $(P=0.041)$ (Supplemental Figure B$4)$.

Finally, preferences of respondents with affected BSA of $3 \%$ to $10 \%$ systematically differed from those of respondents with affected BSA $<3 \%(P=0.004)$ and those of respondents with affected BSA $>10 \%(P<0.001)$ (Supplemental Figure B-5). In contrast, no statistically significant systematic differences in the preferences of respondents with $\mathrm{BSA} \leq 3 \%$ and $\mathrm{BSA}>10 \%$ were observed $(P=0.056)$. 
Although preferences are statistically significantly systematically different between certain pairs of subgroups, the pattern of preference weights and conditional relative attribute importance appears to be qualitatively similar in most cases. That is, these subgroup analyses using RPL do not appear to reveal substantial differences in preferences between subgroups. The only exception is represented by the subgroup based on country of residence, for which preference weight estimates are presented in Supplemental Figure B-6. These results suggest that the patterns of the preference estimates are similar across countries, although lesion reduction was considered relatively more important to respondents in France, Canada, and the United Kingdom (UK) than to other respondents, itching was less important to respondents from Italy, and reducing the risk of impairing side effects was relatively more important to respondents in the UK, Spain, and Canada.

\subsubsection{Subgroup Analysis in the Latent Class Model}

The results of the LC analysis indicate that there are four different segments of respondents in the sample, each with systematically different preferences. However, the LC model presented above does not indicate who is likely to be in each segment. To explore whether the respondent characteristics used in the RPL subgroup analysis can explain which respondents are likely to be in which segment, we used these characteristics as explanatory variables in the class probability model in the LC analysis. Table 4 presents the output of this analysis next to the $P$ values associated with the chi-squared distribution used to test for systematic differences in the RPL subgroups analysis.

When considering these results, it is important to note that, for the class membership probability model to be identified, class 3 is omitted and is the reference for all other model estimates. Therefore, a positive and significant coefficient estimate for a covariate in the class membership probability model is interpreted as increasing the probability that a respondent with this characteristic will be in a specific class rather than class 3 .

The membership probability model for the LC presented in Table 4 shows that most of the coefficients included in the class membership probability model are not statistically different from zero, confirming that most preference heterogeneity is likely to be only weakly linked to the respondent characteristics included in the analysis, as it is not fully captured by any covariates and remains unexplained in this data set. However, examining more in detail the LC membership probability model, it is possible to notice that for some classes, some characteristics are statistically significant. For example, respondents from France, Italy, and Spain are more likely to be in different classes than respondents from the UK and Canada; older respondents are more likely to be in a different class than younger respondents; and respondents with a higher BSA affected are likely to be in a different class than respondents with lower BSA affected. More specifically, respondents from France are less likely to be in class 1 than in class 3 compared with respondents from the UK, while respondents in Italy and Spain are more likely to be in class 4 than in class 3 compared with respondents in the UK. Respondents older than 30 years appear to be more likely to be in class 1 than in class 3 compared with respondents younger than 30 years. Respondents with a BSA higher than 10\% are less likely to be in class 1 and 4 than in class 3 compared with respondents with a BSA lower than $3 \%$. Finally, gender and marital status did not affect the class membership probability. 


\section{Discussion}

This study examined two commonly used methods of controlling for and modelling preference heterogeneity in data generated using a DCE: the RPL with independent random parameters and the LC model, selected as the two most widely used options in health preference assessment. To account for unexplained preference heterogeneity, the former model specification assumes a continuous distribution of preferences across the sample (i.e., preferences are normally distributed around a mean preference across respondents), while the latter assumes a discrete distribution (i.e., preferences are divided into a finite number of groups). This study evaluated, for the first time in a health care application, multiple methods for comparison of two models that are able to account for preference heterogeneity resulting in similar outcomes despite the use of different ways to explicitly control for preference heterogeneity in the model specification. Such analyses have been done in environmental economics [40], but this study is the first health application with different research questions.

Initial comparison of the average results from both RPL and LC models revealed similar mean preference weights and conditional attribute relative importance across model specifications. Consequently, by narrowing the analysis to only the mean estimates, either model would lead to similar empirical conclusions. However, when considering the full model output, including both mean and standard deviations in the RPL model and preference weights specific to each class identified in the LC model, the LC analysis seemed to uncover some preference-heterogeneity patterns that were not evident in the RPL subgroup analysis. It should be noted that these patterns may be a function of the assumptions to account for preference heterogeneity in the model and may not result in significant differences in conclusions between the two analyses when the capacity of both models to explore preference heterogeneity is fully exploited.

Consequently, we compared the same respondent characteristics in a subgroup analysis implemented with the RPL model and in the class membership probability model included in the LC model. Interestingly, in both modeling approaches, country of residence and affected BSA explain preference heterogeneity (although, in the LC model, BSA affects preferences only marginally); however, only the LC model highlights some preference differences associated with age, and only the RPL model highlights systematically different preferences among gender and marital status subgroups.

In addition to the different assumptions about the distribution of preference heterogeneity in the RPL and LC models, the way in which subgroup analyses were conducted using the RPL in this study may explain some of the difference in the results between the RPL and LC models. Specifically, by segmenting the sample into subgroups defined by a single respondent characteristic (e.g., age, gender, country), we assumed that all differences in preferences based on characteristics other than the single characteristic being modeled are captured by the standard deviation estimates in the model. As a result, we do not control for correlation among multiple characteristics in the RPL. In contrast, the LC model considers all modeled respondent characteristics jointly when estimating the class membership function. These results prompt questions of whether the choice of model for incorporating preference heterogeneity matters and, if so, how to judge which approach to modeling unexplained preference heterogeneity 
should be selected. In general, how RPL and LC compare in terms of average preference weight or policy implications is an empirical question. In our case study, LC and RPL models produced the same average results but could lead to different implications if looking at the subgroup analysis and at the different patterns of heterogeneity highlighted in the LC model. The difference is probably caused by the fact that we are making fundamentally different assumptions about how preference heterogeneity works and can be described by the different models.

Provencher and Moore [41] argued that the choice should depend on the researcher's judgment about underlying preferences: preferences that are individual specific are better represented by an RPL model specification, while preferences by clustered groups are better represented by LC model specification. However, according to Hynes et al. [40], who also found different implications from the two modeling approaches, the LC model has an advantage over the RPL approach, as it is a model that can simultaneously estimate marginal preference weights associated with different attribute levels characterizing alternative medical treatments for different groups and can assign the group a probability that can be dependent on the respondent's characteristics. It is therefore possible that the LC model approach, in some cases, could provide a greater range of potentially useful information for public health decision makers. Indeed, in our analysis, the LC model highlighted a pattern of preference heterogeneity across groups that did not appear in the RPL analysis. Still, it is important to note that both models are correct and indicated for preference analysis.

On the basis of the results, we suggest that the final model should be determined by the type of research questions. If the objective of the research is to identify segments in a population for whom alternative approaches to treatment or communication are to be developed, then LC analysis is very likely the correct approach. For example, LC may be best utilized when determining how many health education or outreach programs may be necessary within a population and which factors the education or outreach should address to be most effective within each group [42]. Understanding which patients are in which class can then be used to target the treatment or communication to the appropriate patients within a population.

If instead the objective of the study is to quantify the preferences for a population, an RPL model may be most appropriate. For example, RPL may provide the evidence necessary to demonstrate that patients view the benefits of a treatment to outweigh the risks when a decision is being made to approve a drug or device in a given indication and alternative drugs or devices cannot be designed for different preference segments within the patient population [43]. Subgroup analysis can then be used to explore whether and to what extent the risk-benefit balance differs among patients based on observable characteristics.

Some limitations of the study must be acknowledged. In fact, stated preferences may differ from preferences implied by actual treatment choices, and repeated-choice tasks can cause cognitive fatigue and lead to measurement error. While results from online DCE surveys are often similar to face-to-face interviews, there may be some selection bias resulting from conducting the survey online. Furthermore, the survey respondents constituted a convenience sample and may not be representative of the population of people with psoriasis, potentially limiting the generalizability of the results. Respondents' diagnosis and other clinical characteristics were self-reported and were not verified. 
Finally, the discussion of results from RPL and LC models are empirical findings limited to the data analyzed and the models specified for the analysis, and the results may vary for other studies or different model specifications.

\section{Conclusions}

This study estimates and compares uncorrelated RPL and LC models, which were selected as the two most commonly used options in health preference assessment. Although both explained and unexplained preference heterogeneity can be modeled using both RPL and LC models, the two models explore heterogeneity from different angles. Research should model data using the most adaptable modeling approach to respond to the initial study question. For studies exploring how many groups characterized by different preferences are present in the sample (as in many policy applications), LC analysis is indicated; otherwise RPL can achieve similar if not better results. Random parameter logit and LC also can be compared in terms of preference weights as well as in terms of other preference measures. Since this comparison is an empirical matter, further research may be warranted.

\section{$8 \quad$ Ethics and informed consent}

The research was carried out in compliance with national laws protecting respondents' personal data and with the Codes of Conduct of the European Society for Opinion and Market Research, the European Pharmaceutical Marketing Research Association, and the British Healthcare Business Intelligence Association.

For this study, ethics committee approval was not required, which is in line with the codes of conduct of the relevant Market Research societies. At the beginning of the survey, respondents were asked to explicitly give consent to participate in the study. No clinical data were collected in this study.

\section{Data availability}

The data sets generated and analyzed during the current study are not publicly available due to third party restrictions. The data may be available from Daniel Saure on reasonable request and with permission of Eli Lilly.

\section{Acknowledgments}

The authors gratefully acknowledge Kimberly Moon and Ginger Powell of RTI Health Solution for overall project management for this study and Kate Lothman of RTI Health Solutions for her help during the development of this manuscript. Daniel Saure, Alexander Schacht, and Elisabeth Riedl were involved in the study and in defining research questions. Marco Boeri and Brett Hauber conducted the statistical analysis and interpreted the results. Marco Boeri led development of the manuscript, with input from Brett Hauber. All authors contributed to drafting 
and revising the manuscript, gave final approval of the version to be published, and agree to be accountable for all aspects of the work.

\section{Conflict of Interests}

Marco Boeri, and Brett Hauber are employees of RTI Health Solutions, which received funding from Eli Lilly and Company to conduct the analyses which are the subject of this manuscript. Daniel Saure and Elisabeth Riedl are employees of Eli Lilly and Company. Alexander Schacht was employee of Eli Lilly at the time of writing the manuscript and is now employee of UCB Biosciences.

\section{References}

1. Ryan M, Gerard K, Amaya-Amaya M. Using discrete choice experiments to value health and health care. Dordrecht, the Netherlands: Springer; 2008.

2. Marshall D, Bridges JFP, Hauber AB, et al. Conjoint analysis applications in health - how are studies being designed and reported? An update on current practice in the published literature between 2005 and 2008. Patient. 2010;3(4):249-56.

3. de Bekker-Grob EW, Ryan M, Gerard K. Discrete choice experiments in health economics: a review of the literature. Health Econ. 2010;21(2):145-72.

4. Clark M, Determann D, Petrou S, Moro D, de Bekker-Grob EW. Discrete choice experiments in health economics: a review of the literature. Pharmacoeconomics. 2014;32:883-902.

5. Soekhai V, de Bekker-Grob EW, Ellis AR, Vass CM. Discrete choice experiments in health economics: past, present and future. Pharmacoeconomics. 2019;37(2):201-26.

6. Ashcroft DM, Seston E, Griffiths CE. Trade-offs between the benefits and risks of drug treatment for psoriasis: a discrete choice experiment with U.K. dermatologists. Br J Dermatol. 2006;155:1236-41.

7. Schaarschmidt ML, Umar N, Schmieder A, et al. Patient preferences for psoriasis treatments: impact of treatment experience. J Eur Acad Dermatol Venereol. 2013;27(2):187-98.

8. Gonzalez JM, Johnson FR, McAteer H, Posner J, Mughal F. Comparing preferences for outcomes of psoriasis treatments among patients and dermatologists in the U.K.: results from a discrete-choice experiment. Br J Dermatol. 2017;176(3):777-85. doi: 10.1111/bjd.14798. 
9. Fairchild AO, Reed SD, Johnson FR, Anglin G, Wolka AM, Noel RA. What is clearance worth? Patients' stated risk tolerance for psoriasis treatments. J Dermatolog Treat. 2017;28(8):709-15. doi:10.1080/09546634.2017.1329499.

10. Alcusky M, Lee S, Lau G, et al. Dermatologist and patient preferences in choosing treatments for moderate to severe psoriasis. Dermatol Ther. 2017 Dec;7(4):463-83. doi: 10.1007/s13555-017-0205-2.

11. Umar N, Yamamoto S, Loerbroks A, Terris D. Elicitation and use of patients' preferences in the treatment of psoriasis: a systematic review. Acta Derm Venereol. 2012;92:339-409

12. Hauber AB, Gonzalez JM, Schenkel B, Lofland JH, Martin S. The value to patients of reducing lesion severity in plaque psoriasis. J Dermatolog Treat. 2011;22:266-75.

13. Kromer C, Schaarschmidt ML, Schmieder A, Herr R, Goerdt S, Peitsch WK. Patient preferences for treatment of psoriasis with biologicals: a discrete choice experiment. PLOS One. 2015 Jun 9;10(6):e0129120. doi:10.1371/journal.pone.0129120.

14. Feldman S, Moeller A, Idemyr S, Gonzalez JM. Relative importance of mode of administration in treatment preferences among plaque psoriasis patients in the United States. J Health Econ Outcomes Res. 2016;4(2):141-57.

15. Christophers E, Griffiths CE, Gaitanis G, van de Kerkhof P. The unmet treatment need for moderate to severe psoriasis: results of a survey and chart review. J Eur Acad Dermatol Venereol. 2006 Sep;20(8):9215 .

16. Kauf T, Yang JC, Kimball AB, et al. Psoriasis patients' willingness to accept side-effect risks for improved treatment efficacy. J Dermatol Treat. 2015;26(6):507-13.

17. Kjaer T, Bech M, Gyrd-Hansen D, Hart-Hansen K. Ordering effect and price sensitivity in discrete choice experiments: need we worry? Health Econ. 2006;15:1217-28.

18. Schaarschmidt ML, Schmieder A, Umar N, et al. Patient preferences for psoriasis treatments: process characteristics can outweigh outcome attributes. Arch Dermatol. 2011;147:1285-94.

19. Schmieder A, Schaarschmidt ML, Umar N, et al. Comorbidities significantly impact patients' preferences for psoriasis treatments. J Am Acad Dermatol. 2012;67:363-72.

20. Seston EM, Ashcroft DM, Griffiths CE. Balancing the benefits and risks of drug treatment: a statedpreference, discrete choice experiment with patients with psoriasis. Arch Dermatol. 2007;143:1175-9. 
21. McFadden D. Conditional logit analysis of qualitative choice-behaviour. In: Zarembka P, editor. Frontiers in econometrics. New York, NY: Academic Press; 1973. pp. 105-42.

22. Train K. Recreation demand models with taste variation over people. Land Econ. 1998;74(2):230-9.

23. Spoth R, Ball AD, Klose A, Redmond C. Illustration of a market segmentation technique using familyfocused prevention program preference data. Health Educ Res. 1996;11(2):259-67.

24. Mentzakis E, Ryan M, McNamee P. Using discrete choice experiments to value informal care tasks: exploring preference heterogeneity. Health Econ. 2011;20:930-44. doi: 10.1002/hec.1656.

25. Zhou M, Thayer MW, Bridges JFP. Using latent class analysis to model preference heterogeneity in health: a systematic review. Pharmacoeconomics. 2018;36(2):175-87.

26. Sawtooth Software, Inc. CBC User Manual. Sequim: Sawtooth Software; 1999.

27. Thurstone LL. A law of comparative judgment. Psychol Rev. 1927;34:273-86.

28. Manski C. The structure of random utility models. Theory Dec. 1977;8:229-54.

29. McFadden D, Train K. Mixed MNL models for discrete response. J Appl Econ (Chichester Engl). 2000;15(5):447-70.

30. Hauber AB, Gonzalez JM, Groothuis-Oudshoorn CGM, et al. Statistical methods for the analysis of discrete choice experiments: a report of the ISPOR conjoint analysis good research practices task force. Value Health. 2016 Jun;19(4):300-15.

31. Hess S, Rose J. Can scale and coefficient heterogeneity be separated in random coefficients models? Transportation. 2012;39(6):1225-39.

32. Train K. Discrete choice methods with simulation. Cambridge, UK: Cambridge University Press; 2009.

33. Hess S, Train K, Polak J. On the use of a modified Latin hypercube sampling (MLHS) method in the estimation of a mixed logit model for vehicle choice. Transp Res Part B Methodolog. 2006;40(2):147-67.

34. Greene WH, Hensher DA. A latent class model for discrete choice analysis: contrasts with mixed logit. Transp Res Part B Methodolog. 2003;37(8):681-98.

35. Hurvich M, Tsai C. Regression and time series model selection in small samples. Biometrika. 1989;76(2):297-307.

36. McLachlan G, Peel D. Finite mixture models. New York, NY: John Wiley \& Sons; 2000. 
37. Wedel M, Kamakura W. Market segmentation: conceptual and methodological foundations. 2nd ed. Boston, MA: Kluwer Academic Publishers; 2000.

38. Leroux BG. Consistent estimation of mixing distributions. Ann Stat. 1992;20:1350-60.

39. Thiene M, Galletto L, Scarpa R, Boatto V. Determinants of WTP for prosecco wine. Brit Food J. 2013;115(2):279-99.

40. Hynes S, Hanley N, Scarpa R. Effects on welfare measures of alternative means of accounting for preference heterogeneity in recreational demand models. Am J Agr Econ. 2008;90(4):1011-27.

41. Provencher B, Moore R. A discussion of "using angler characteristics and attitudinal data to identify environmental preference classes.” Environ Res Econ. 2006;34(1):117-24.

42. Cunningham CE, Kostrzewa L, Rimas H, et al. Modeling organizational justice improvements in a pediatric health service: a discrete-choice conjoint experiment. Patient. 2013;6(1):45-59.

43. Ho MP, Gonzalez JM, Lerner HP, et al. Incorporating patient-preference evidence into regulatory decision making. Surg Endosc. 2015 Oct;29(10):2984-93. 


\section{Tables}

Table 1. Attributes and Levels for the Choice Questions

\begin{tabular}{|c|c|c|}
\hline Attribute Labels & Levels & $\begin{array}{c}\text { Variable Used } \\
\text { in the Model }\end{array}$ \\
\hline \multirow{5}{*}{$\begin{array}{l}\text { Mode and frequency of administration } \\
\text { (presented as "dosage form") }\end{array}$} & Ointment (daily) & DOSE1 \\
\hline & Tablet (once a week) & DOSE2 \\
\hline & Injection (1-2 times per month) & DOSE3 \\
\hline & $\begin{array}{l}\text { Phototherapy }{ }^{\mathrm{a}} \text { (in phases, several times a } \\
\text { week) }\end{array}$ & DOSE4 \\
\hline & Injection (4 times per year) & DOSE $^{\mathrm{b}}$ \\
\hline \multirow{4}{*}{$\begin{array}{l}\text { Time to reach clinically meaningful results } \\
\text { (presented as "time to reach results") }\end{array}$} & After 2 weeks & TIME1 \\
\hline & After 4 weeks & TIME2 \\
\hline & After 3 months & TIME3 \\
\hline & After 6 months & TIME4 $^{\mathrm{b}}$ \\
\hline \multirow{4}{*}{$\begin{array}{l}\text { Reduction in psoriasis lesions including } \\
\text { plaques (presented as "results: skin") }\end{array}$} & $100 \%$ reduction of psoriasis spots & SKIN1 \\
\hline & $90 \%$ reduction of psoriasis spots & SKIN2 \\
\hline & $75 \%$ reduction of psoriasis spots & SKIN3 \\
\hline & $50 \%$ reduction of psoriasis spots & SKIN4 ${ }^{\mathrm{b}}$ \\
\hline \multirow{3}{*}{$\begin{array}{l}\text { Reduction in itching } \\
\text { (presented as "results: itching") }\end{array}$} & No itching at all & ITCH1 \\
\hline & Less itching & ITCH2 \\
\hline & No change in itching & ITCH$^{\mathrm{b}}$ \\
\hline \multirow{4}{*}{$\begin{array}{l}\text { Risk of moderate-to-severe side effects } \\
\text { (presented as "risk of impairing side effects") }\end{array}$} & Very high risk ( 1 in 10$)$ & IMP1 \\
\hline & High risk ( 1 in 100$)$ & IMP2 \\
\hline & Low risk ( 1 in 1,000$)$ & IMP3 \\
\hline & Very low risk $(1$ in 10,000$)$ & IMP4 $4^{b}$ \\
\hline \multirow{3}{*}{$\begin{array}{l}\text { Side effects manifestation } \\
\text { (presented as "appearance of side effects") }\end{array}$} & Permanently (throughout the therapy) & APP1 \\
\hline & Temporary (during therapy) & APP2 \\
\hline & In phases (when starting the therapy) & $\mathrm{APP}^{\mathrm{b}}$ \\
\hline
\end{tabular}

a Presented to respondent as "PUVA/Light therapy, phototherapy (in phases, several times a week)."

${ }^{\mathrm{b}}$ Omitted during estimation to have an identifiable model and then recovered as the negative sum of the coefficients on the nonexcluded levels of the attribute. The standard error of the recovered coefficient on the omitted level was then recovered mathematically using the delta method (WALD command in NLOGIT5).

${ }^{c}$ Depending on personal circumstances, this could be headaches, nausea, vomiting, common cold, or other side effects.

Note: the presentation of the levels used in the choice questions were slightly different from those included in the choice question presented to respondents in the survey instrument (see Figure 2 for an example of choice question). 
Table 2. Descriptions of Subgroups Considered for Subgroup Analyses

\begin{tabular}{|c|c|c|}
\hline Subgroup Description & Subgroups Explored & $\begin{array}{l}\text { Sample Size } \\
(\mathrm{N}=\mathbf{1 , 1 2 3})\end{array}$ \\
\hline \multirow[t]{5}{*}{ Country } & Canada & $163(14.5 \%)$ \\
\hline & France & $253(22.5 \%)$ \\
\hline & Italy & $245(21.8 \%)$ \\
\hline & Spain & $249(22.2 \%)$ \\
\hline & UK & $213(19.0 \%)$ \\
\hline \multirow[t]{2}{*}{ Age subgroup pair 1} & Below median age (39 years) & $542(48.3 \%)$ \\
\hline & Median age (39 years) or older & $581(51.7 \%)$ \\
\hline \multirow[t]{2}{*}{ Age subgroup pair 2} & Younger than 30 years & $248(22.1 \%)$ \\
\hline & Aged 30 years or older & $875(77.9 \%)$ \\
\hline \multirow[t]{2}{*}{ Gender } & Female & $619(55.1 \%)$ \\
\hline & Male & $504(44.9 \%)$ \\
\hline \multirow[t]{3}{*}{ Marital status } & Married & $565(50.3 \%)$ \\
\hline & Single & $267(23.8 \%)$ \\
\hline & Other marital status & $291(25.9 \%)$ \\
\hline \multirow[t]{3}{*}{ BSA affected } & BSA affected $<3 \%$ & $361(32.1 \%)$ \\
\hline & BSA affected $3 \%$ to $10 \%$ & $434(38.6 \%)$ \\
\hline & BSA affected $>10 \%$ & $328(29.2 \%)$ \\
\hline
\end{tabular}

BSA = body surface area; UK = United Kingdom. 
Table 3. Descriptive Statistics of Respondent Characteristics $(N=1,123)$

\begin{tabular}{|c|c|}
\hline Question & $\begin{array}{c}\text { Respondents }(\mathrm{N}=1,123), \\
\text { n }(\%)\end{array}$ \\
\hline Age: Mean (SD) & $40.6(12.8)$ \\
\hline \multicolumn{2}{|l|}{ Gender } \\
\hline Female & $619(55.1 \%)$ \\
\hline Male & $504(44.9 \%)$ \\
\hline \multicolumn{2}{|c|}{ Please tell which of the following best describes your current status } \\
\hline Full-time employed & $695(61.9 \%)$ \\
\hline Part-time employed & $149(13.3 \%)$ \\
\hline Studying/in education/training & $54(4.8 \%)$ \\
\hline Employed but on sick leave & $15(1.3 \%)$ \\
\hline Looking after home & $42(3.7 \%)$ \\
\hline Unemployed & $55(4.9 \%)$ \\
\hline Retired & $87(7.7 \%)$ \\
\hline Other & $26(2.3 \%)$ \\
\hline \multicolumn{2}{|c|}{$\begin{array}{l}\text { Which of the following best describes your marital/relationship } \\
\text { status? }\end{array}$} \\
\hline Single & $267(23.8 \%)$ \\
\hline Married & $565(50.3 \%)$ \\
\hline Cohabiting with partner & $179(15.9 \%)$ \\
\hline In a relationship/not cohabiting & $78(6.9 \%)$ \\
\hline Other & $34(3.0 \%)$ \\
\hline \multicolumn{2}{|c|}{ Which of the following best describes your level of education? } \\
\hline High school/secondary school education & $304(27.1 \%)$ \\
\hline College & $252(22.4 \%)$ \\
\hline Undergraduate degree & $329(29.3 \%)$ \\
\hline Masters/PhD & $210(18.7 \%)$ \\
\hline Other & $28(2.5 \%)$ \\
\hline
\end{tabular}

$\mathrm{SD}=$ standard deviation 
Table 4. $\quad P$ Values for the Random-Parameters Logit Subgroups Analysis and Membership

Probability Model for the Latent Class, Including Patient Characteristics Used for the

Subgroup Analysis ( $=1,123)$

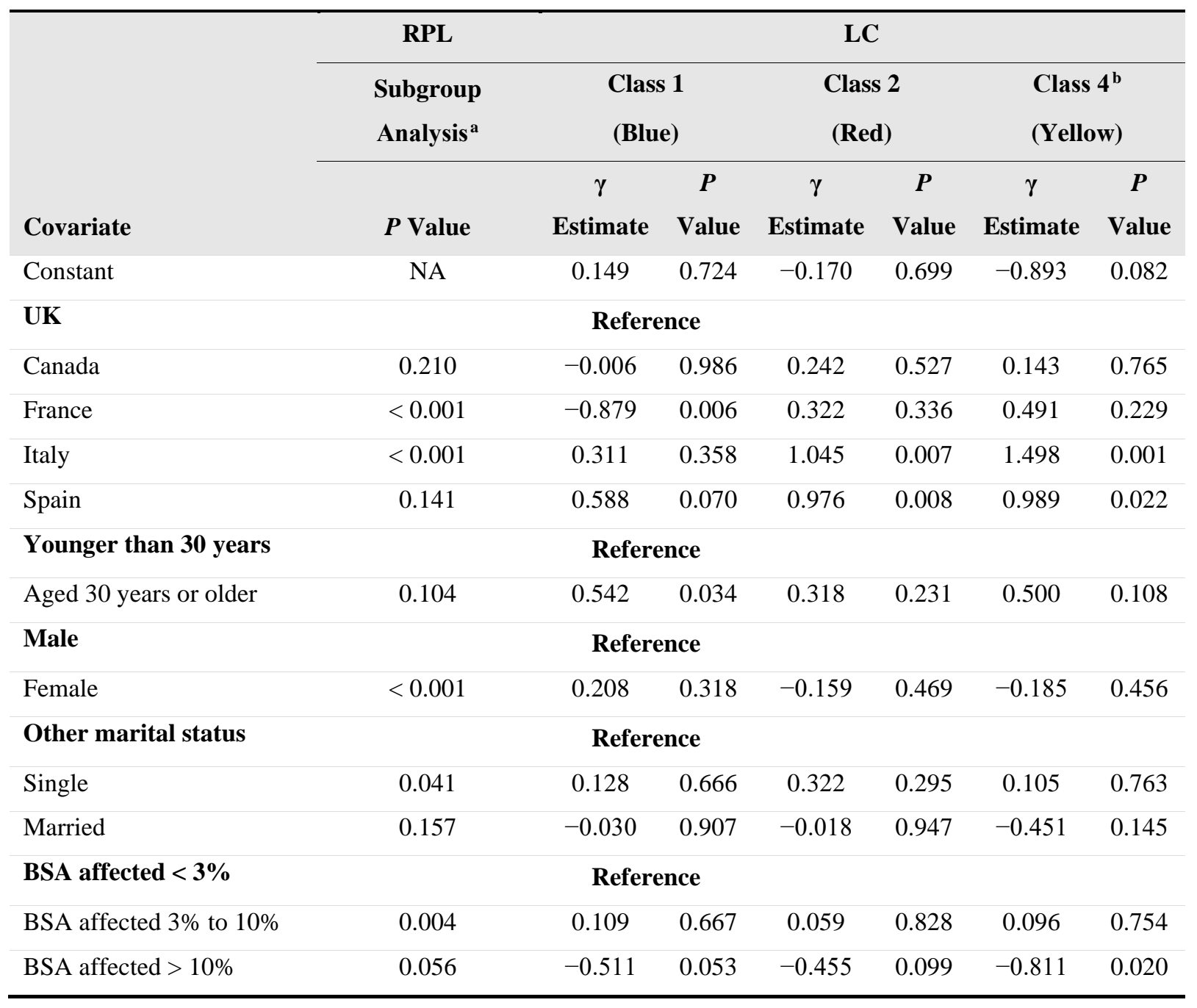

BSA = body surface area; $\mathrm{LC}=$ latent class, NA = not applicable; RPL = random-parameters logit, UK = United Kingdom.

${ }^{a} P$ values are associated with the chi-squared distribution of the joint test used to test for systematic differences in the RPL subgroups analysis.

${ }^{\mathrm{b}}$ For identification purposes, class 3 is fixed to zero and used as a reference.

Note: In the preference model, the statistical significance is relative to the mean effect of the attribute (because we effects coded the levels, the mean effect is equal to zero). In the membership probability model, the covariates are categorical dummy coded with coefficients relative to the baseline dummy variable (namely, below 30 years of age, BSA $<3 \%$, other civil status, male, and resident in the UK). It is possible to use overall likelihood tests for analysis in which more than two subgroups were included and, for the LC model, to test whether each set of covariates influences the probability of belonging to a certain class. We found that all subgroups, except the one defined by marital status, were significantly different overall and all the covariates included in the LC model significantly impacted the probability function. 


\section{Figures}

Figure 1. Sample Flow Diagram

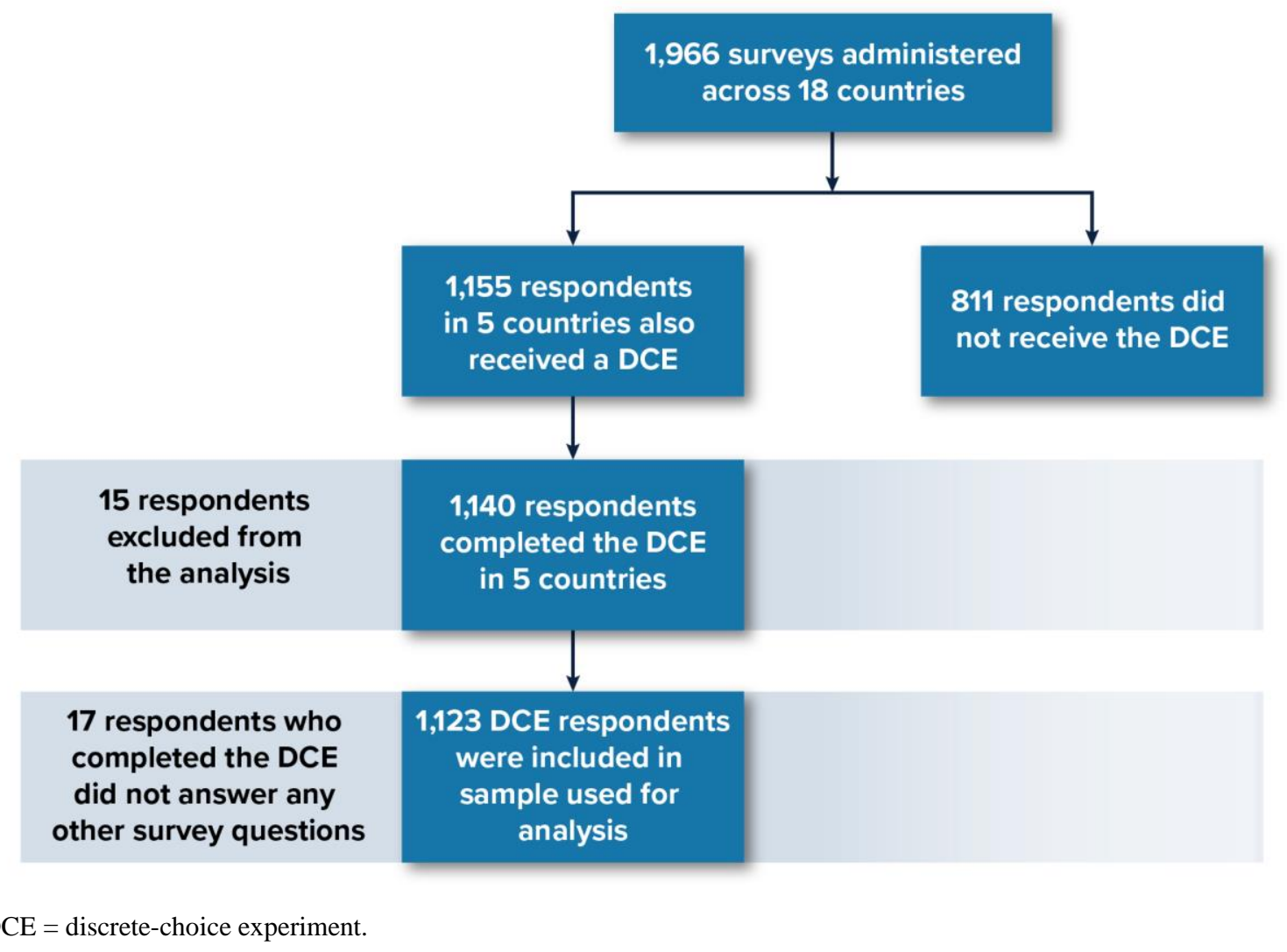


Figure 2. Example of a Choice Question Presented in the Patient Survey

\begin{tabular}{|l|c|c|c|}
\hline Dosage form & Option 1 & Option 2 & Option 3 \\
\hline Time to reach results & $\begin{array}{c}\text { Injection } \\
\text { (4 times per year) }\end{array}$ & $\begin{array}{c}\text { Tablet } \\
\text { (once a week) }\end{array}$ & $\begin{array}{c}\text { Ointment } \\
\text { (daily) }\end{array}$ \\
\hline Results: skin & $\begin{array}{c}\text { A0\% reduction of } \\
\text { psoriasis spots }\end{array}$ & $\begin{array}{c}\text { 75\% reduction of } \\
\text { psoriasis spots }\end{array}$ & $\begin{array}{c}\text { 50\% reduction of } \\
\text { psoriasis spots }\end{array}$ \\
\hline Results: itching & Less itching & No change in itching & No itching at all \\
\hline $\begin{array}{l}\text { Risk of impairing } \\
\text { side effects }\end{array}$ & $\begin{array}{c}\text { Low risk of impairing } \\
\text { side effects (1 of 1,000) }\end{array}$ & $\begin{array}{c}\text { Low risk of impairing } \\
\text { side effects (1 of 1,000) }\end{array}$ & $\begin{array}{c}\text { High risk of impairing } \\
\text { side effects (1 of 100) }\end{array}$ \\
\hline $\begin{array}{l}\text { Appearance of } \\
\text { side effects }\end{array}$ & $\begin{array}{c}\text { Temporary } \\
\text { (during therapy) }\end{array}$ & $\begin{array}{c}\text { Temporary } \\
\text { (during therapy) }\end{array}$ & $\begin{array}{c}\text { Temporary } \\
\text { (during therapy) }\end{array}$ \\
\hline & O & $\bigcirc$ & O \\
\hline
\end{tabular}


Figure 3. Comparison of Mean Preference Weight Estimates From Random-Parameters Logit and Latent Class Models $(\mathrm{N}=\mathbf{1 , 1 2 3})$

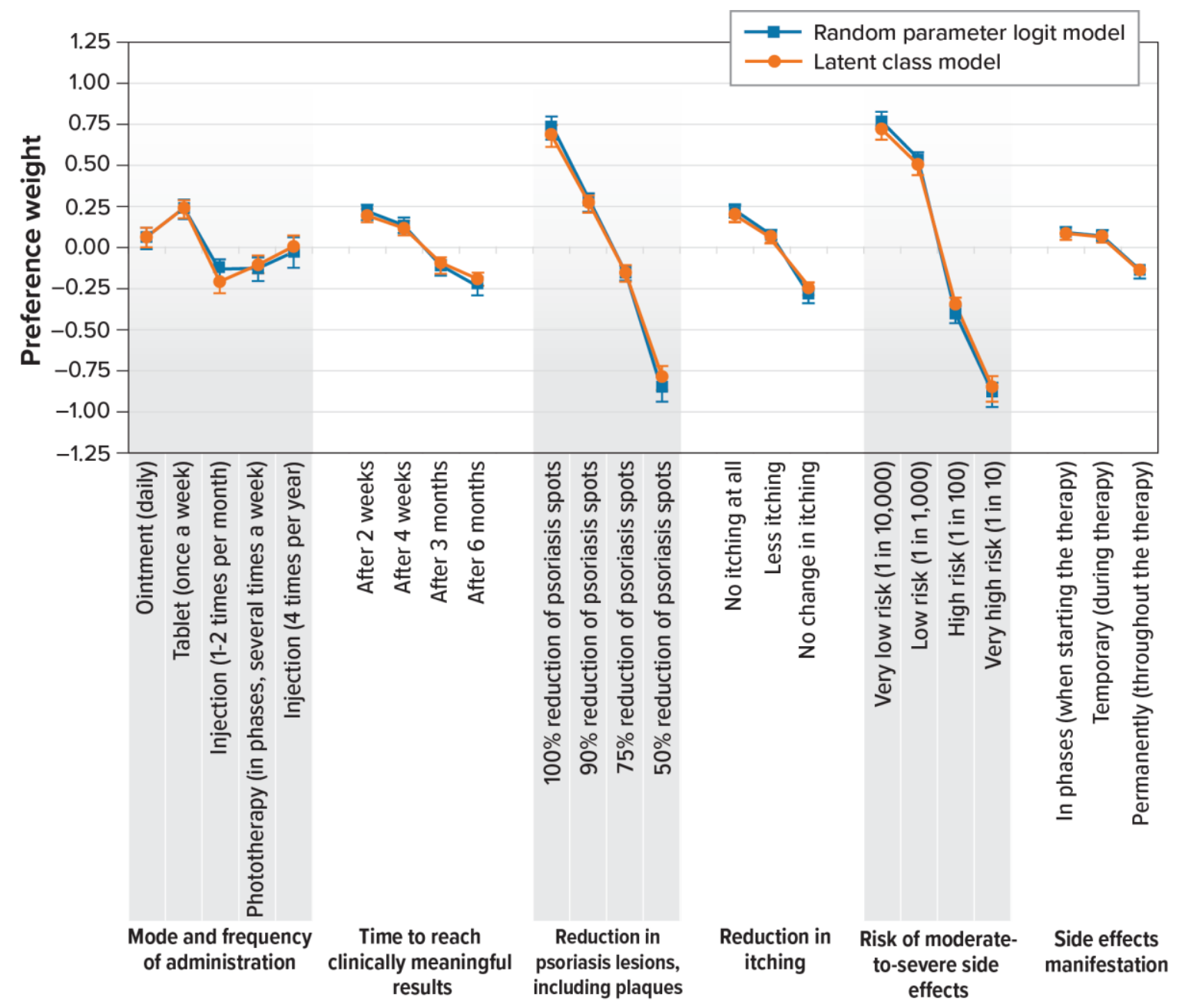

Notes: This figure plots the mean preference weight estimate for each attribute level derived from both the random-parameters logit and latent class models.

The vertical bars surrounding each mean preference weight denote the $95 \%$ confidence interval (standard errors for the omitted levels were computed by delta method). 
Figure 4. Latent Class Model: Preference Weights by Class $(\mathrm{N}=1,123)$

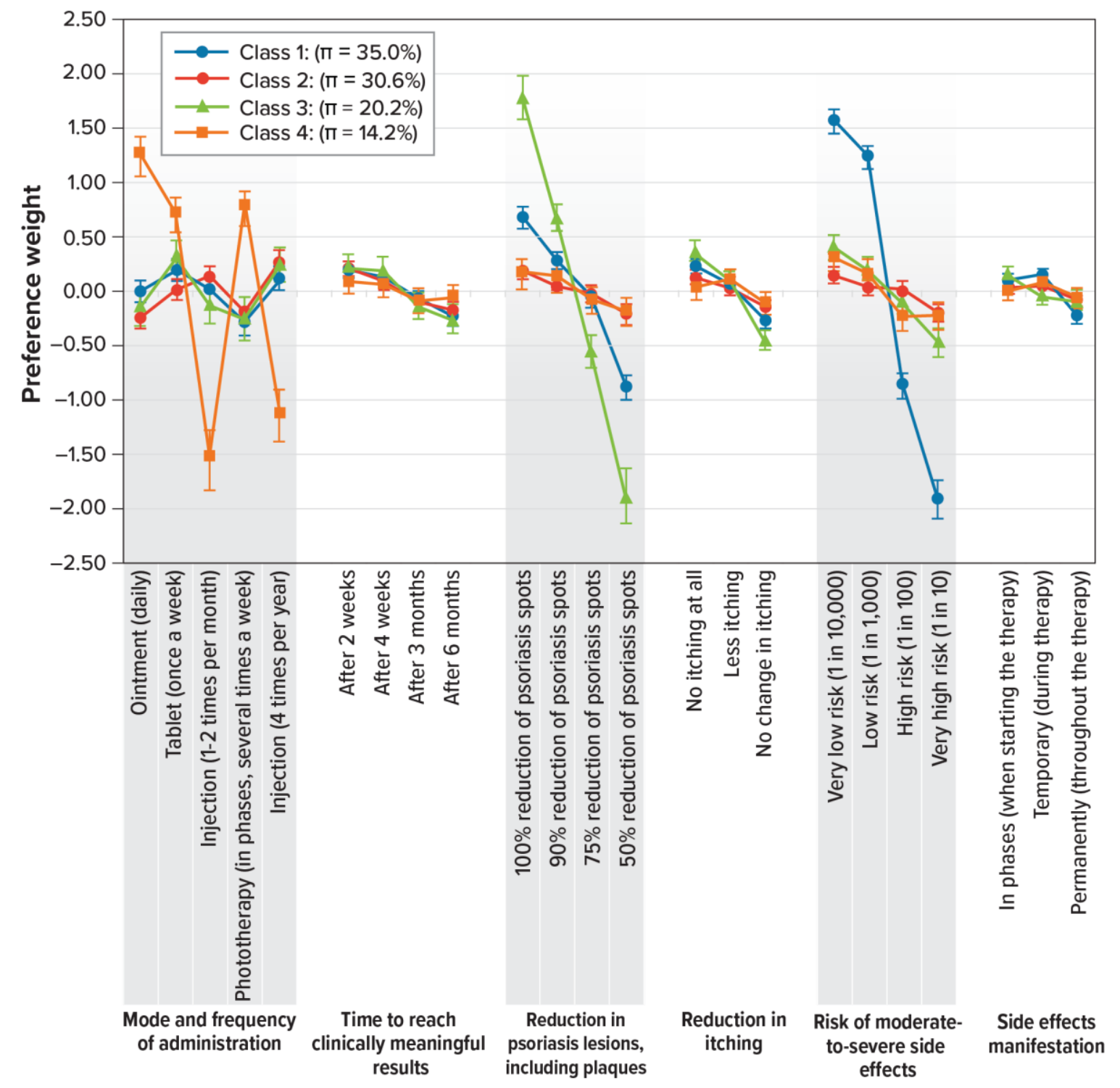

$\pi=$ class membership probability (sample average).

Note: The vertical bars surrounding each mean preference weight denote the $95 \%$ confidence interval (standard errors for the omitted levels were computed by delta method). 


\section{Modeling Heterogeneity in Patients' Preferences for Psoriasis Treatments in a Multicountry Study: A Comparison Between Random-Parameters Logit and Latent Class Approaches}

\section{Supplemental Material for Web Only Format}

Marco Boeri ${ }^{1}$, Daniel Saure ${ }^{2}$, Katharine Thorn ${ }^{2}$, Alexander Schacht ${ }^{2}$, Brett Hauber ${ }^{3}$

${ }^{1}$ RTI Health Solutions, Belfast, UK;

${ }^{2}$ Eli Lilly and Company;

${ }^{3}$ RTI Health Solutions, Research Triangle Park, NC, USA 
Appendix A. Main-Effects Model Outputs 
Table A-1. Random-Parameters Model: Mean Preference Weight and Standard Deviation Estimates $(\mathbf{N}=\mathbf{1 , 1 2 3})$

\begin{tabular}{|c|c|c|c|c|c|}
\hline Attribute & Levels & $\begin{array}{c}\text { Coefficient } \\
\text { Estimate }\end{array}$ & $P$ Value & $\begin{array}{l}\text { Standard } \\
\text { Deviation }\end{array}$ & $P$ Value \\
\hline \multirow{5}{*}{$\begin{array}{l}\text { Mode and frequency } \\
\text { of administration }\end{array}$} & Ointment (daily) & 0.061 & 0.089 & 0.788 & $<0.001$ \\
\hline & Tablet (once a week) & 0.233 & $<0.001$ & 0.443 & $<0.001$ \\
\hline & Injection (1-2 times per month) & -0.135 & $<0.001$ & 0.286 & $<0.001$ \\
\hline & $\begin{array}{l}\text { Phototherapy (in phases, several } \\
\text { times a week) }\end{array}$ & -0.132 & $<0.001$ & 0.735 & $<0.001$ \\
\hline & Injection (4 times per year) & -0.026 & 0.5682 & 2.252 & $<0.001$ \\
\hline \multirow{4}{*}{$\begin{array}{l}\text { Time to reach } \\
\text { clinically meaningful } \\
\text { results }\end{array}$} & After 2 weeks & 0.214 & $<0.001$ & 0.364 & $<0.001$ \\
\hline & After 4 weeks & 0.134 & $<0.001$ & 0.054 & 0.542 \\
\hline & After 3 months & -0.118 & $<0.001$ & 0.023 & 0.7072 \\
\hline & After 6 months & -0.230 & $<0.001$ & 0.441 & $<0.001$ \\
\hline \multirow{4}{*}{$\begin{array}{l}\text { Reduction in } \\
\text { psoriasis lesions, } \\
\text { including plaques }\end{array}$} & $100 \%$ reduction of psoriasis spots & 0.731 & $<0.001$ & 0.760 & $<0.001$ \\
\hline & $90 \%$ reduction of psoriasis spots & 0.273 & $<0.001$ & 0.309 & $<0.001$ \\
\hline & $75 \%$ reduction of psoriasis spots & -0.150 & $<0.001$ & 0.107 & 0.4149 \\
\hline & $50 \%$ reduction of psoriasis spots & -0.853 & $<0.001$ & 1.176 & $<0.001$ \\
\hline \multirow[t]{3}{*}{ Reduction in itching } & No itching at all & 0.220 & $<0.001$ & 0.343 & $<0.001$ \\
\hline & Less itching & 0.067 & $<0.001$ & 0.065 & 0.2499 \\
\hline & No change in itching & -0.287 & $<0.001$ & 0.408 & $<0.001$ \\
\hline \multirow{4}{*}{$\begin{array}{l}\text { Risk of moderate-to- } \\
\text { severe side effects }\end{array}$} & Very high risk (1 in 10$)$ & -0.890 & $<0.001$ & 0.688 & $<0.001$ \\
\hline & High risk (1 in 100) & -0.407 & $<0.001$ & 0.348 & $<0.001$ \\
\hline & Low risk $(1$ in 1,000$)$ & 0.539 & $<0.001$ & 0.052 & 0.403 \\
\hline & Very low risk $(1$ in 10,000$)$ & 0.758 & $<0.001$ & 1.089 & $<0.001$ \\
\hline \multirow[t]{3}{*}{$\begin{array}{l}\text { Side effects } \\
\text { manifestation }\end{array}$} & $\begin{array}{l}\text { Permanently (throughout the } \\
\text { therapy) }\end{array}$ & -0.149 & $<0.001$ & 0.193 & $<0.001$ \\
\hline & Temporary (during therapy) & 0.070 & $<0.001$ & 0.098 & 0.0252 \\
\hline & $\begin{array}{l}\text { In phases (when starting the } \\
\text { therapy) }\end{array}$ & 0.080 & $<0.001$ & 0.291 & $<0.001$ \\
\hline
\end{tabular}

Note: The statistical significance is relative to the mean effect of the attribute (because we effect-coded the levels, the mean effect is equal to zero). 
Table A-2. $\quad$ Latent Class Model: Preference Weight and Membership Probability Covariates Estimates $(\mathrm{N}=1,123)$

\begin{tabular}{|c|c|c|c|c|c|c|c|c|c|c|c|}
\hline \multirow[b]{2}{*}{ Attribute } & \multirow[b]{2}{*}{ Levels } & \multicolumn{2}{|c|}{ Class $\mathbf{1}, \mathbf{3 5 . 0 \%}$} & \multicolumn{2}{|c|}{ Class 2, $\mathbf{3 0 . 6 \%}$} & \multicolumn{2}{|c|}{ Class 3, 20.2\% } & \multicolumn{2}{|c|}{ Class $4,14.2 \%$} & \multicolumn{2}{|c|}{$\begin{array}{c}\text { Mean Across } \\
\text { Classes* }\end{array}$} \\
\hline & & $\begin{array}{c}\beta \\
\text { Estimate }\end{array}$ & $\begin{array}{c}P \\
\text { Value }\end{array}$ & $\begin{array}{c}\beta \\
\text { Estimate }\end{array}$ & $\begin{array}{c}P \\
\text { Value }\end{array}$ & $\begin{array}{c}\beta \\
\text { Estimate }\end{array}$ & $\begin{array}{c}P \\
\text { Value }\end{array}$ & $\begin{array}{c}\beta \\
\text { Estimate }\end{array}$ & $\begin{array}{c}P \\
\text { Value }\end{array}$ & $\begin{array}{c}\beta \\
\text { Estimate }\end{array}$ & $\begin{array}{c}P \\
\text { Value }\end{array}$ \\
\hline \multirow{5}{*}{$\begin{array}{l}\text { Mode and } \\
\text { frequency of } \\
\text { administration }\end{array}$} & Ointment (daily) & -0.011 & 0.834 & -0.248 & $<0.001$ & -0.160 & 0.046 & 1.243 & $<0.001$ & 0.065 & 0.032 \\
\hline & Tablet (once a week) & 0.191 & $<0.001$ & 0.017 & 0.717 & 0.306 & $<0.001$ & 0.702 & $<0.001$ & 0.234 & $<0.001$ \\
\hline & $\begin{array}{l}\text { Injection (1-2 times per } \\
\text { month) }\end{array}$ & -0.004 & 0.937 & 0.126 & 0.009 & -0.136 & 0.117 & -1.552 & $<0.001$ & -0.211 & $<0.001$ \\
\hline & $\begin{array}{l}\text { Phototherapy (in phases, } \\
\text { several times a week) }\end{array}$ & -0.290 & $<0.001$ & -0.181 & 0.002 & -0.262 & 0.010 & 0.767 & $<0.001$ & -0.101 & $<0.001$ \\
\hline & Injection (4 times per year) & 0.113 & 0.031 & 0.285 & $<0.001$ & 0.252 & 0.001 & -1.159 & $<0.001$ & 0.013 & 0.677 \\
\hline \multirow{4}{*}{$\begin{array}{l}\text { Time to reach } \\
\text { clinically } \\
\text { meaningful } \\
\text { results }\end{array}$} & After 2 weeks & 0.194 & $<0.001$ & 0.207 & $<0.001$ & 0.213 & 0.001 & 0.093 & 0.117 & 0.187 & $<0.001$ \\
\hline & After 4 weeks & 0.123 & 0.004 & 0.080 & 0.019 & 0.191 & 0.001 & 0.061 & 0.322 & 0.115 & $<0.001$ \\
\hline & After 3 months & -0.087 & 0.038 & -0.116 & 0.001 & -0.144 & 0.015 & -0.086 & 0.156 & -0.107 & $<0.001$ \\
\hline & After 6 months & -0.229 & $<0.001$ & -0.171 & $<0.001$ & -0.260 & $<0.001$ & -0.068 & 0.282 & -0.195 & $<0.001$ \\
\hline $\begin{array}{l}\text { Reduction in } \\
\text { psoriasis }\end{array}$ & $\begin{array}{l}100 \% \text { reduction of psoriasis } \\
\text { spots }\end{array}$ & 0.669 & $<0.001$ & 0.199 & $<0.001$ & 1.782 & $<0.001$ & 0.159 & 0.011 & 0.678 & $<0.001$ \\
\hline $\begin{array}{l}\text { lesions, } \\
\text { including }\end{array}$ & $\begin{array}{l}90 \% \text { reduction of psoriasis } \\
\text { spots }\end{array}$ & 0.278 & $<0.001$ & 0.048 & 0.186 & 0.668 & $<0.001$ & 0.118 & 0.062 & 0.264 & $<0.001$ \\
\hline \multirow[t]{2}{*}{ plaques } & $\begin{array}{l}75 \% \text { reduction of psoriasis } \\
\text { spots }\end{array}$ & -0.061 & 0.152 & -0.024 & 0.507 & -0.562 & $<0.001$ & -0.082 & 0.180 & -0.154 & $<0.001$ \\
\hline & $\begin{array}{l}50 \% \text { reduction of psoriasis } \\
\text { spots }\end{array}$ & -0.886 & $<0.001$ & -0.223 & $<0.001$ & -1.888 & $<0.001$ & -0.195 & 0.006 & -0.788 & $<0.001$ \\
\hline
\end{tabular}




\begin{tabular}{|c|c|c|c|c|c|c|c|c|c|c|c|}
\hline \multirow[b]{2}{*}{ Attribute } & \multirow[b]{2}{*}{ Levels } & \multicolumn{2}{|c|}{ Class $\mathbf{1 , 3 5 . 0 \%}$} & \multicolumn{2}{|c|}{ Class 2, 30.6\% } & \multicolumn{2}{|c|}{ Class 3, 20.2\% } & \multicolumn{2}{|c|}{ Class $4,14.2 \%$} & \multicolumn{2}{|c|}{$\begin{array}{c}\text { Mean Across } \\
\text { Classes* }\end{array}$} \\
\hline & & $\begin{array}{c}\beta \\
\text { Estimate }\end{array}$ & $\begin{array}{c}P \\
\text { Value }\end{array}$ & $\begin{array}{c}\beta \\
\text { Estimate }\end{array}$ & $\begin{array}{c}P \\
\text { Value }\end{array}$ & $\begin{array}{c}\beta \\
\text { Estimate }\end{array}$ & $\begin{array}{c}P \\
\text { Value }\end{array}$ & $\begin{array}{c}\beta \\
\text { Estimate }\end{array}$ & $\begin{array}{c}P \\
\text { Value }\end{array}$ & $\begin{array}{c}\beta \\
\text { Estimate }\end{array}$ & $\begin{array}{c}P \\
\text { Value }\end{array}$ \\
\hline \multirow{3}{*}{$\begin{array}{l}\text { Reduction in } \\
\text { itching }\end{array}$} & No itching at all & 0.221 & $<0.001$ & 0.133 & $<0.001$ & 0.362 & $<0.001$ & 0.019 & 0.686 & 0.194 & $<0.001$ \\
\hline & Less itching & 0.059 & 0.066 & 0.019 & 0.479 & 0.090 & 0.046 & 0.101 & 0.033 & 0.059 & $<0.001$ \\
\hline & No change in itching & -0.280 & $<0.001$ & -0.152 & $<0.001$ & -0.452 & $<0.001$ & -0.119 & 0.013 & -0.253 & $<0.001$ \\
\hline \multirow{4}{*}{$\begin{array}{l}\text { Risk of } \\
\text { moderate-to- } \\
\text { severe side } \\
\text { effects }\end{array}$} & Very high risk ( 1 in 10 ) & -1.916 & $<0.001$ & -0.200 & $<0.001$ & -0.467 & $<0.001$ & -0.230 & $<0.001$ & -0.859 & $<0.001$ \\
\hline & High risk (1 in 100) & -0.861 & $<0.001$ & 0.015 & 0.675 & -0.121 & 0.038 & -0.238 & $<0.001$ & -0.355 & $<0.001$ \\
\hline & Low risk ( 1 in 1,000$)$ & 1.221 & $<0.001$ & 0.038 & 0.315 & 0.186 & 0.004 & 0.162 & 0.007 & 0.499 & $<0.001$ \\
\hline & Very low risk ( 1 in 10,000$)$ & 1.556 & $<0.001$ & 0.147 & $<0.001$ & 0.403 & $<0.001$ & 0.306 & $<0.001$ & 0.714 & $<0.001$ \\
\hline \multirow[t]{3}{*}{$\begin{array}{l}\text { Side effects } \\
\text { manifestation }\end{array}$} & $\begin{array}{l}\text { Permanently (throughout the } \\
\text { therapy) }\end{array}$ & -0.235 & $<0.001$ & -0.085 & 0.003 & -0.094 & 0.051 & -0.073 & 0.127 & -0.138 & $<0.001$ \\
\hline & Temporary (during therapy) & 0.141 & $<0.001$ & 0.043 & 0.124 & -0.040 & 0.375 & 0.067 & 0.172 & 0.064 & $<0.001$ \\
\hline & $\begin{array}{l}\text { In phases (when starting the } \\
\text { therapy) }\end{array}$ & 0.094 & 0.004 & 0.042 & 0.130 & 0.134 & 0.004 & 0.006 & 0.911 & 0.074 & $<0.001$ \\
\hline \multicolumn{2}{|c|}{ Class membership probability model } & \multicolumn{10}{|c|}{ Reference class } \\
\hline \multirow{2}{*}{\multicolumn{12}{|c|}{ Reference }} \\
\hline & & & & & & & & & & & \\
\hline & Canada & -0.006 & 0.986 & 0.242 & 0.527 & 0 & & 0.143 & 0.765 & \multicolumn{2}{|l|}{ NA } \\
\hline & France & -0.879 & 0.006 & 0.322 & 0.336 & 0 & & 0.491 & 0.229 & \multicolumn{2}{|l|}{ NA } \\
\hline & Italy & 0.311 & 0.358 & 1.045 & 0.007 & 0 & & 1.498 & 0.001 & \multicolumn{2}{|l|}{ NA } \\
\hline & Spain & 0.588 & 0.070 & 0.976 & 0.008 & 0 & & 0.989 & 0.022 & \multicolumn{2}{|l|}{ NA } \\
\hline & Younger than 30 years & \multicolumn{2}{|c|}{ Reference } & & & & & & & & \\
\hline & Aged 30 years or older & 0.542 & 0.034 & 0.318 & 0.231 & 0 & & 0.500 & 0.108 & \multicolumn{2}{|l|}{ NA } \\
\hline
\end{tabular}




\begin{tabular}{|c|c|c|c|c|c|c|c|c|c|c|c|}
\hline \multirow[b]{2}{*}{ Attribute } & \multirow[b]{2}{*}{ Levels } & \multicolumn{2}{|c|}{ Class $\mathbf{1 ,} 35.0 \%$} & \multicolumn{2}{|c|}{ Class $2, \mathbf{3 0 . 6 \%}$} & \multicolumn{2}{|c|}{ Class 3, 20.2\% } & \multicolumn{2}{|c|}{ Class $4,14.2 \%$} & \multicolumn{2}{|c|}{$\begin{array}{c}\text { Mean Across } \\
\text { Classes* }\end{array}$} \\
\hline & & $\begin{array}{c}\beta \\
\text { Estimate }\end{array}$ & $\begin{array}{c}P \\
\text { Value }\end{array}$ & $\begin{array}{c}\beta \\
\text { Estimate }\end{array}$ & $\begin{array}{c}P \\
\text { Value }\end{array}$ & $\begin{array}{c}\beta \\
\text { Estimate }\end{array}$ & $\begin{array}{c}P \\
\text { Value }\end{array}$ & $\begin{array}{c}\beta \\
\text { Estimate }\end{array}$ & $\begin{array}{c}P \\
\text { Value }\end{array}$ & $\begin{array}{c}\beta \\
\text { Estimate }\end{array}$ & $\begin{array}{c}P \\
\text { Value }\end{array}$ \\
\hline \multicolumn{12}{|c|}{ Reference } \\
\hline & Female & 0.208 & 0.318 & -0.159 & 0.469 & 0 & & -0.185 & 0.456 & NA & \\
\hline & Other marital status & \multicolumn{2}{|c|}{ Reference } & & & & & & & & \\
\hline & Single & 0.128 & 0.666 & 0.322 & 0.295 & 0 & & 0.105 & 0.763 & NA & \\
\hline & Married & -0.030 & 0.907 & -0.018 & 0.947 & 0 & & -0.451 & 0.145 & NA & \\
\hline & BSA affected $<3 \%$ & \multicolumn{2}{|c|}{ Reference } & & & & & & & & \\
\hline & BSA affected $3 \%$ to $10 \%$ & 0.109 & 0.667 & 0.059 & 0.828 & 0 & & 0.096 & 0.754 & NA & \\
\hline & BSA affected $>10 \%$ & -0.511 & 0.053 & -0.455 & 0.099 & 0 & & -0.811 & 0.020 & NA & \\
\hline
\end{tabular}

BSA = body surface area; NA = not applicable; UK = United Kingdom.

* The mean preference weights across classes is the average of the preference weights for each class weighted by the respective class membership probability interval (standard errors for the omitted levels were computed by delta method).

Note: in the preference model, the statistical significance is relative to the mean effect of the attribute (because we effects coded the levels, the mean effect is equal to zero). In the membership probability model, the statistical significance of the categorical dummy-coded coefficients is relative to the reference dummy variable (namely, "Male," "Below

30 years of age," "BSA < 3\%," "Other civil status," and "UK"). For identification purposes, the parameter estimated in the class membership probability of class 3 is fixed to zero as this class is used as a reference. 
Table A-3. Goodness-of-Fit Measures for the Various Model Specifications $(\mathbf{N}=1,123)$

\begin{tabular}{|c|c|c|c|c|c|c|c|c|c|}
\hline Model & $\begin{array}{l}\text { Null Log- } \\
\text { Likelihood }\end{array}$ & $\begin{array}{l}\text { Final Log- } \\
\text { Likelihood }\end{array}$ & $\begin{array}{l}\text { K (\# } \\
\text { Par) }\end{array}$ & $\begin{array}{c}\text { Pseudo- } \\
\text { rho }^{2}\end{array}$ & $\mathrm{Chi}^{2}$ & BIC & AIC & 3AIC & $\begin{array}{c}\text { Corrected } \\
\text { AIC }\end{array}$ \\
\hline MNL & $-15,025.7$ & $-13,050.8$ & 17 & 0.130 & $3,949.8$ & $26,263.6$ & $26,135.671$ & $26,152.7$ & $26,136.5$ \\
\hline RPL & $-15,025.7$ & $-12,160.4$ & 34 & 0.188 & $5,730.7$ & $24,644.5$ & $24,388.704$ & $24,422.7$ & $24,395.0$ \\
\hline \multicolumn{10}{|l|}{ Latent class } \\
\hline 2 classes & $-15,025.7$ & $-12,496.1$ & 35 & 0.166 & $5,059.2$ & $25,325.6$ & $25,062.290$ & $25,097.3$ & $25,069.1$ \\
\hline 3 classes & $-15,025.7$ & $-12,112.9$ & 53 & 0.190 & $5,825.6$ & $24,730.6$ & $24,331.821$ & $24,384.8$ & $24,354.9$ \\
\hline 4 classes $*$ & $-15,025.7$ & $-11,892.5$ & 71 & 0.204 & $6,266.4$ & $24,461.3$ & $23,927.084$ & $23,998.01$ & $23,981.9$ \\
\hline 5 classes & $-15,025.7$ & $-11,824.5$ & 89 & 0.207 & $6,402.4$ & $24,496.6$ & $23,826.996$ & $23,916.0$ & $23,934.3$ \\
\hline
\end{tabular}

$\mathrm{AIC}=$ Akaike information criterion; $\mathrm{BIC}=$ Bayesian information criterion; Obs. $=$ Observations; $\mathrm{MNL}=$ multinomial logit RPL $=$ random-parameters logit

* The latent class model with 4 classes was selected and included in the results. 
Figure A-1. Goodness-of fit measures for the various latent class model specifications, by number of classes included $(\mathrm{N}=\mathbf{1 , 1 2 3})$
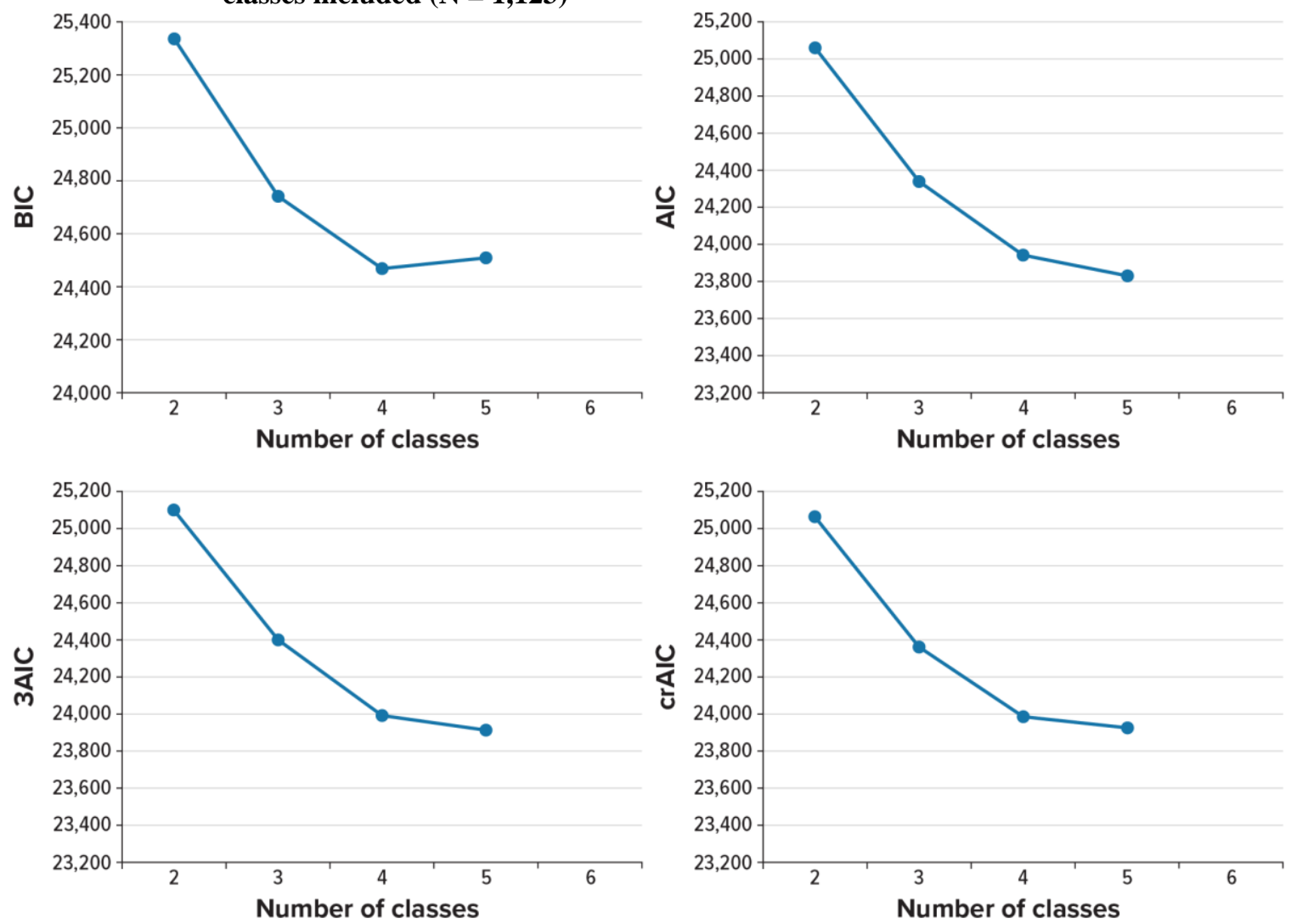

$\mathrm{BIC}=$ Bayesian information criterion $; \mathrm{AIC}=$ Akaike information criterion 


\section{Appendix B. Additional Figures: Preference Weights From RPL Subgroup Analysis}


Figure B-1. Random-Parameters Logit Preference Weights Subgroup by Gender $(\mathrm{N}=\mathbf{1 , 1 2 3})$

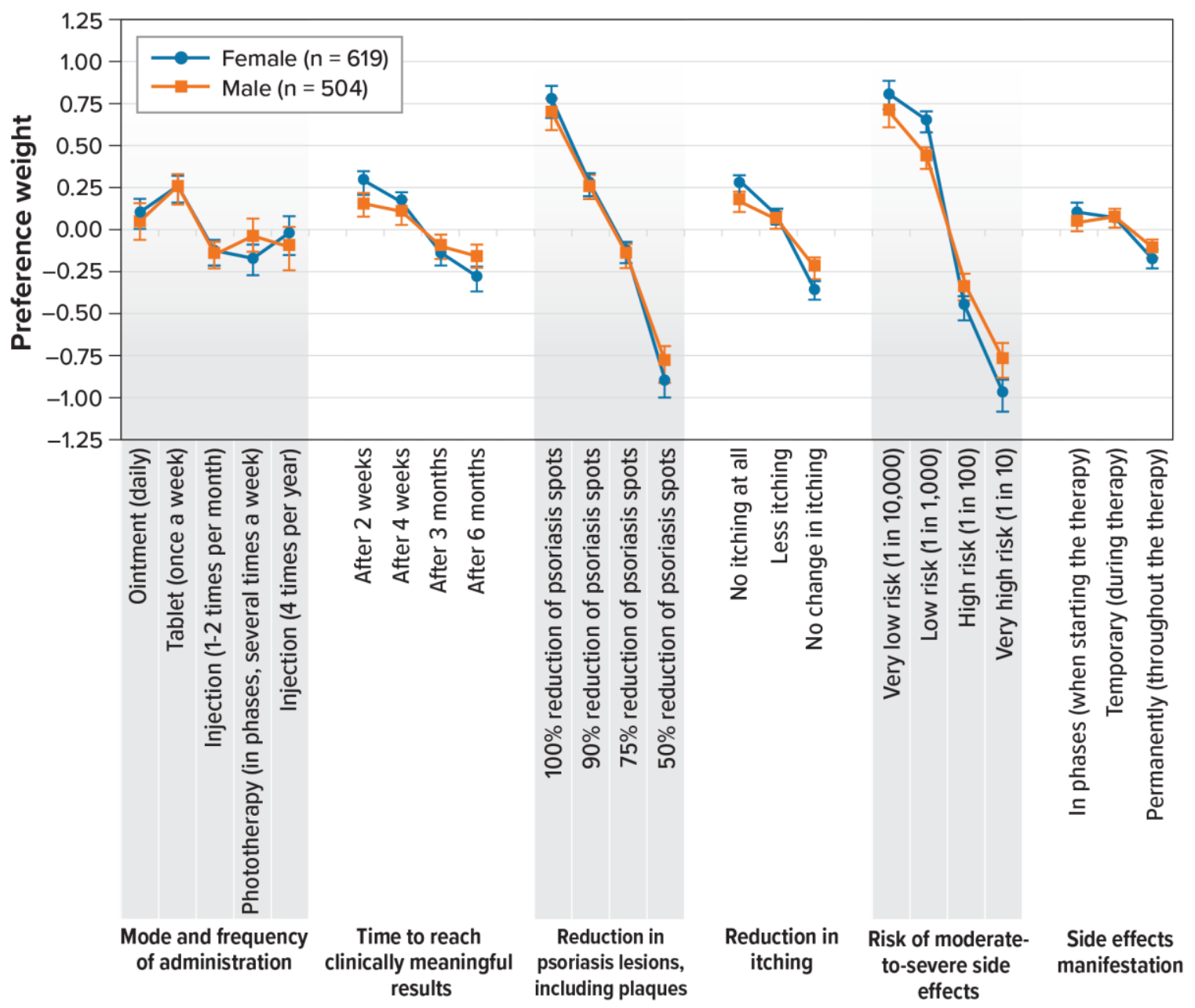

Note: The vertical bars surrounding each mean preference weight denote the $95 \%$ confidence interval (standard errors for the omitted levels were computed by delta method). 
Figure B-2. Random-Parameters Logit Preference Weights Subgroup 1 by Age (Median 39 Years of Age, $\mathbf{N}=1,123$ )

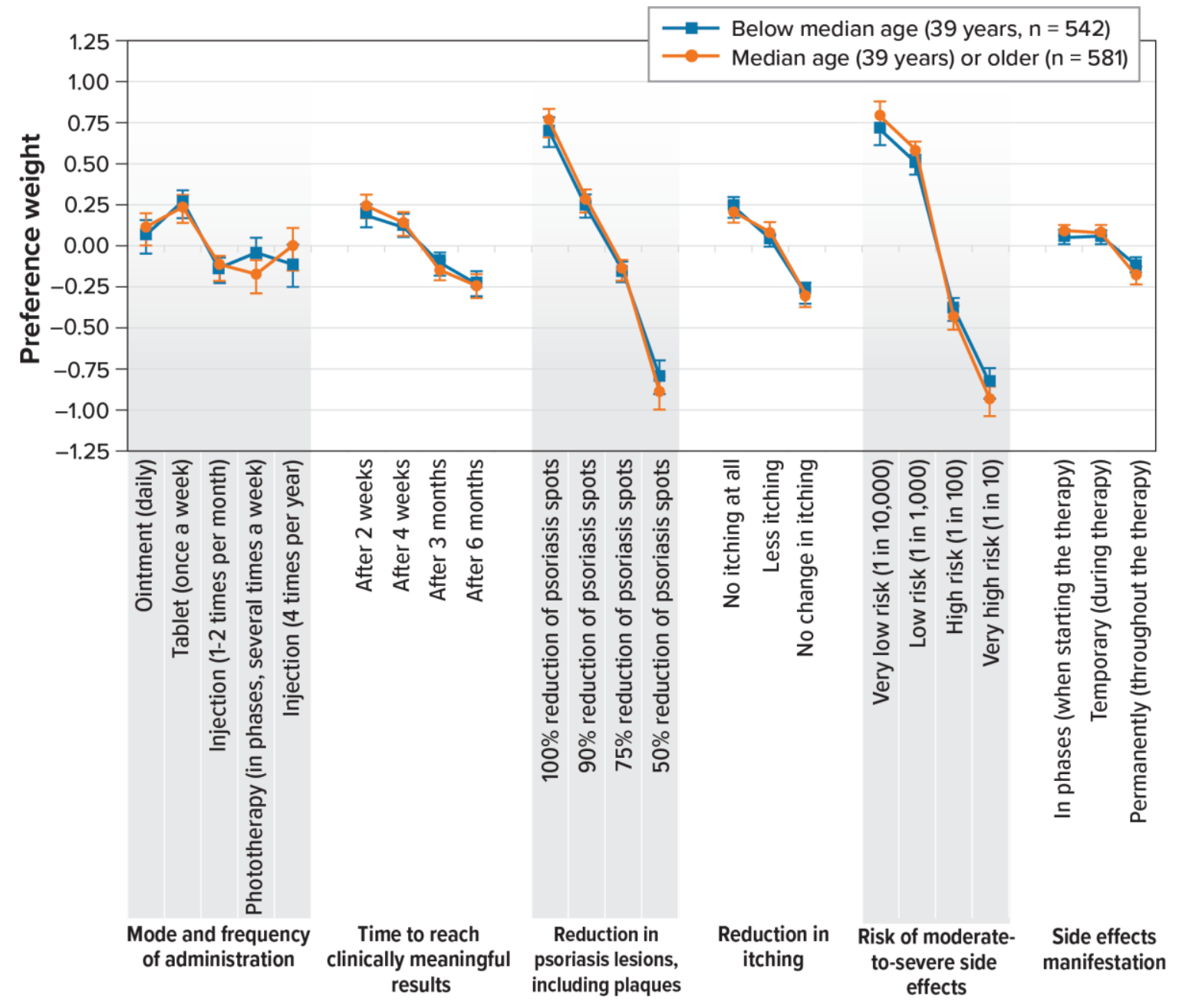

Note: The vertical bars surrounding each mean preference weight denote the $95 \%$ confidence interval (standard errors for the omitted levels were computed by delta method). 
Figure B-3. Random-Parameters Logit Preference Weights Subgroup 2 by Age (30 Years of Age, $\mathrm{N}=1,123$ )

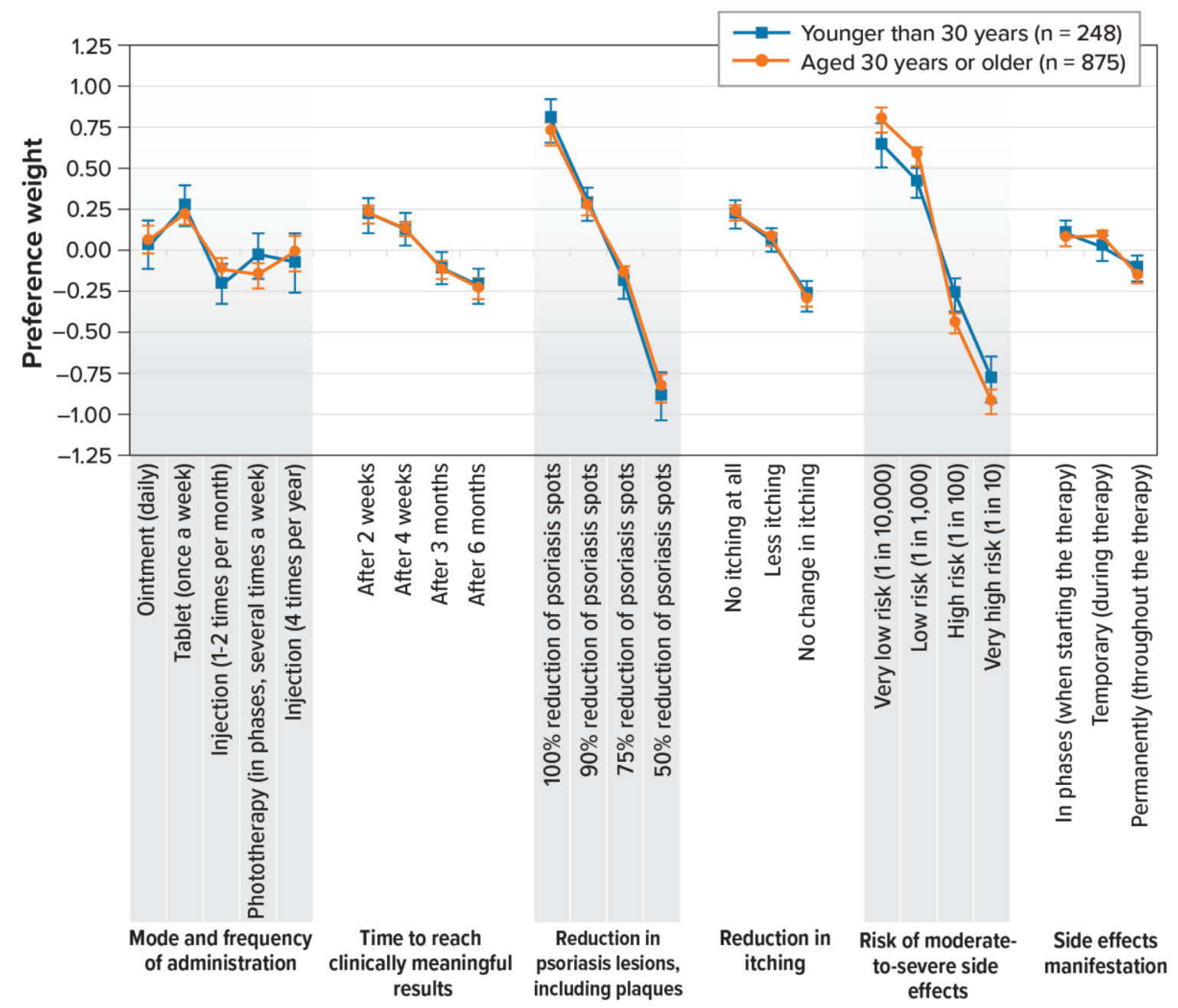

Note: The vertical bars surrounding each mean preference weight denote the $95 \%$ confidence interval (standard errors for the omitted levels were computed by delta method). 
Figure B-4. Random-Parameters Logit Preference Weights Subgroup by Marital Status $(\mathrm{N}=1,123)$

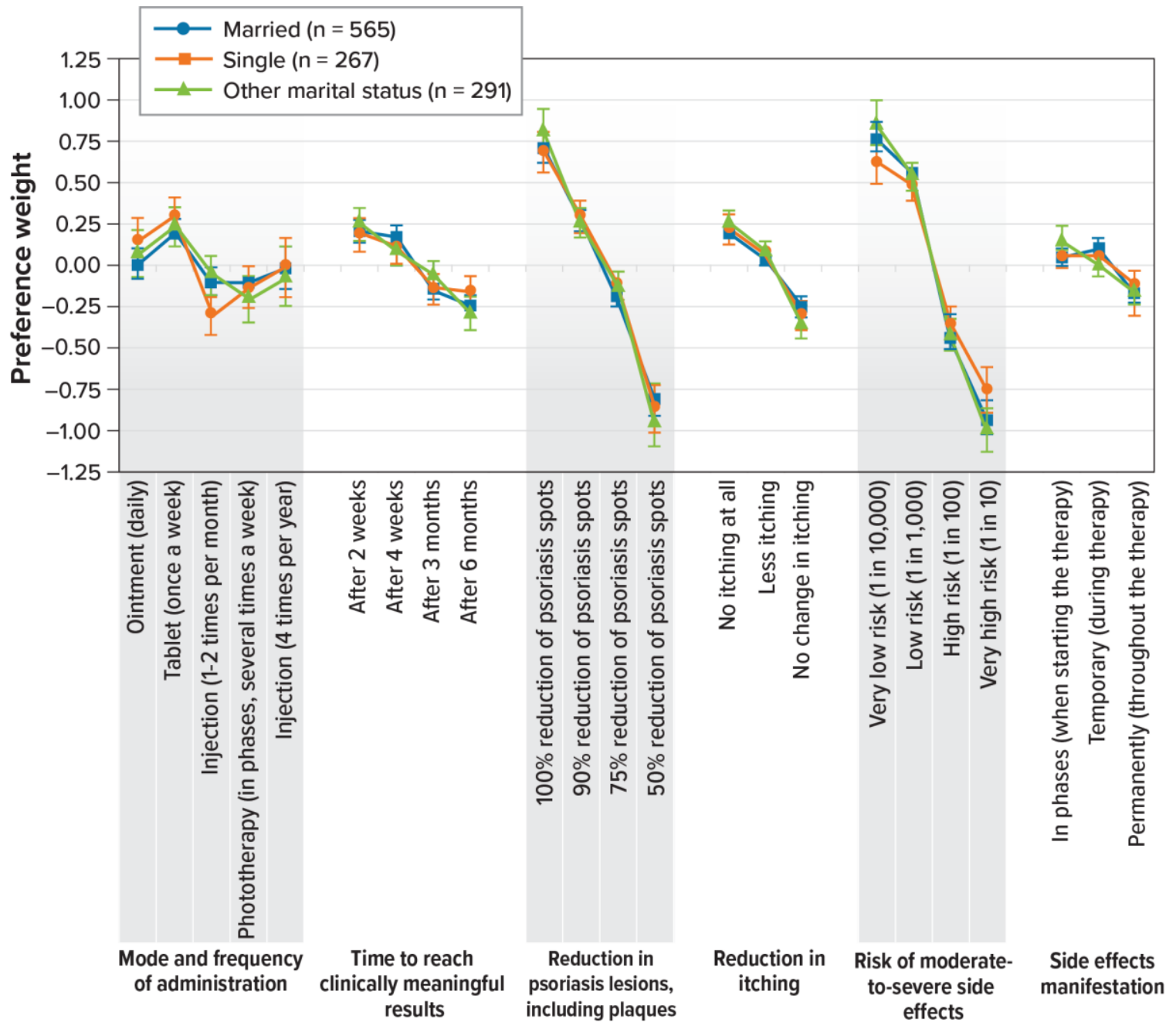

Note: The vertical bars surrounding each mean preference weight denote the $95 \%$ confidence interval (standard errors for the omitted levels were computed by delta method). 
Figure B-5. Random-Parameters Logit Preference Weights Subgroup by Severity as Measured by the Patient's Current Body Surface Area Affected $(\mathrm{N}=1,123)$

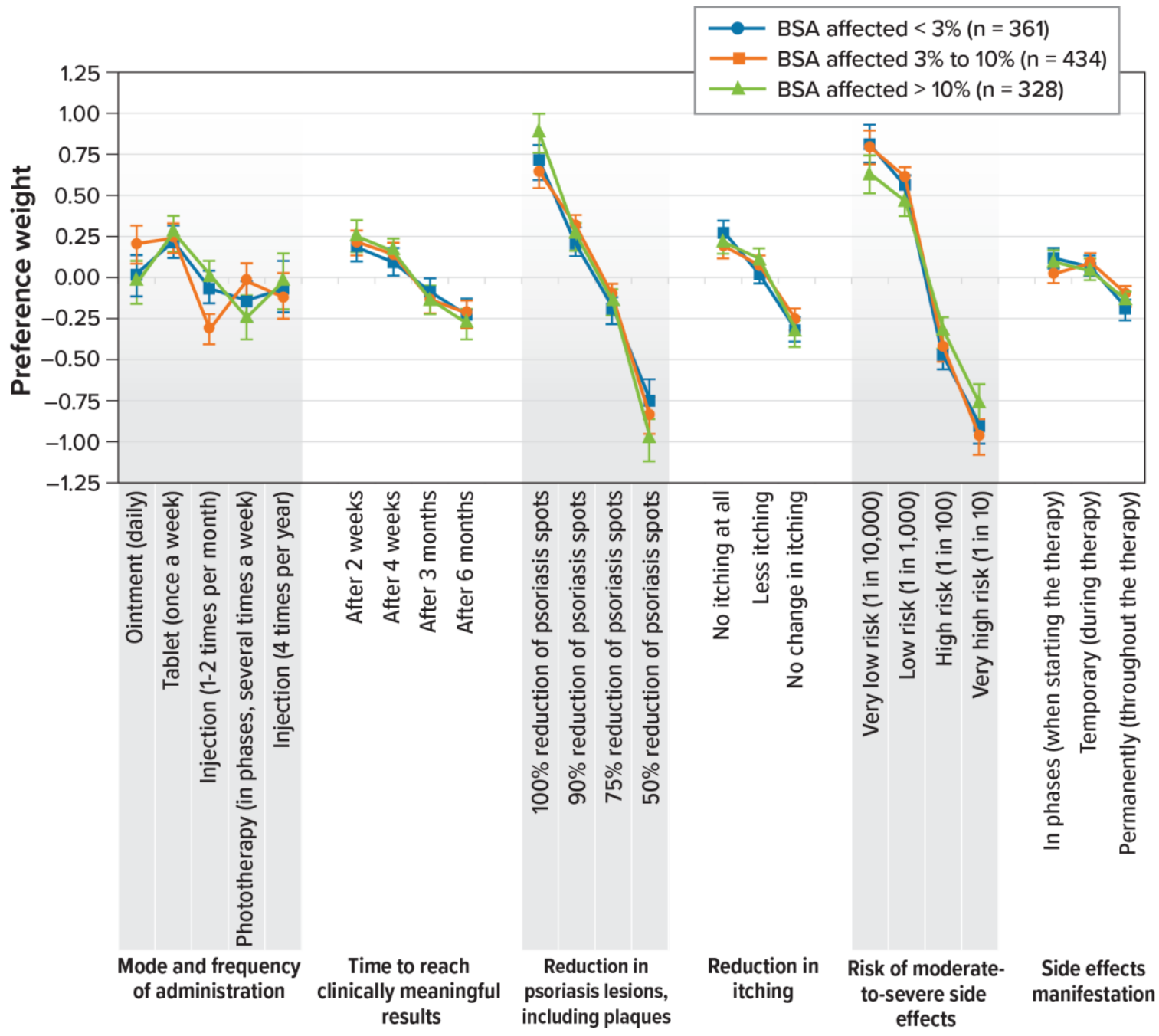

$\mathrm{BSA}=$ body surface area.

Note: The vertical bars surrounding each mean preference weight denote the $95 \%$ confidence interval (standard errors for the omitted levels were computed by delta method). 
Figure B-6. Random-Parameters Logit Preference Weights Subgroup by Country $(\mathbf{N}=1,123)$

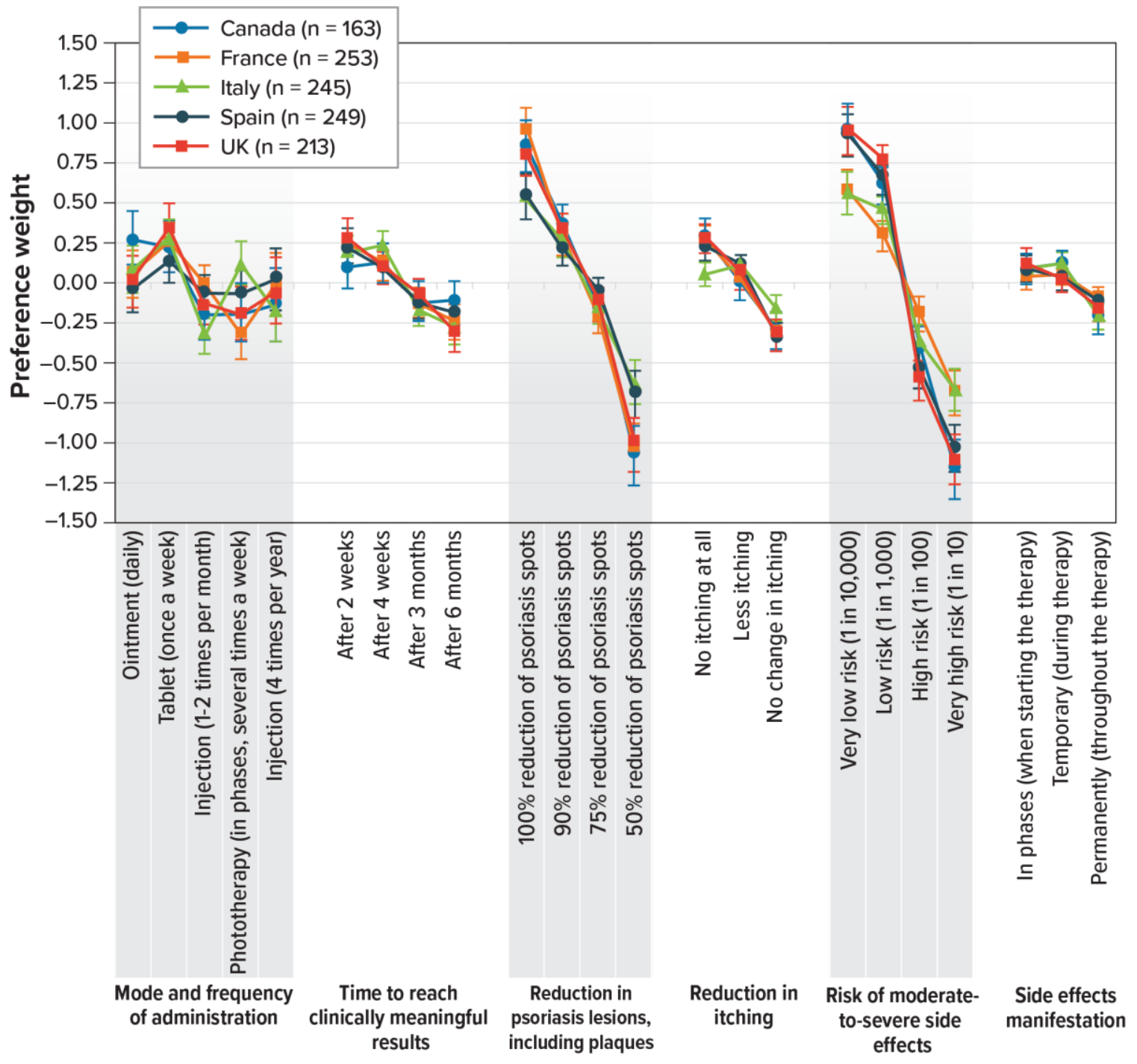

UK = United Kingdom .

Note: The vertical bars surrounding each mean preference weight denote the $95 \%$ confidence interval (standard errors for the omitted levels were computed by delta method). 